\title{
LA INNOVACIÓN COMO BASE DEL RELACIONAMIENTO CON PROVEEDORES
}

\author{
Enrique Alania Vera \\ Investigador independiente
}

\begin{abstract}
Resumen:
La búsqueda de la innovación no tiene un camino definido y es posible propiciar y generar la innovación desde un gran comprador. Para este fin clientes y proveedores deben generar un ambiente de colaboración donde sea posible tener esquemas de sinergias entre ellos. Del entendimiento de los mecanismos de contratación, se pueden buscar mecanismos de generación de ideas de innovación que busquen resolver problemas operativos y que a la par, generen valor al crear productos nuevos, mejorando con ello la posición competitiva del proveedor, del comprador (cliente) y del país.
\end{abstract}

Palabras clave:

Innovación, Proveedores, Clientes, Contratos, Problemas operativos, Colaboración, Oportunismo, Confianza. 


\title{
Innovation at the base of provider's relationships
}

\begin{abstract}
:
The innovation does not have a model or path previously defined so it is possible to promote the innovation since the demand so a key factor is the big buyer. For this purpose, it is important to generate an environment of collaboration between customers and suppliers. It is relevant to understand the mechanism to do contracts so the key customer could be promote new ideas to solve operating problems and the same time increase the competitive position of supplier, customer and the country.
\end{abstract}

\section{Keywords:}

Innovation, Providers, Customers, Contracts, Operational problems, Collaboration, Opportunism, Trust in business relationships.

\section{Enrique Alania Vera}

Doctor en Administración de Negocios por Maastricht School of Management, Holanda; Doctor en Administración Estratégica de Empresas por la Pontificia Universidad Católica del Perú; Master of Philosophy por Maastricht School of Management, Holanda; MBA por la Universidad del Pacífico de Lima, Perú; Estudios de Postgrado en el Instituto Tecnológico de Massachusetts (MIT), Estados Unidos y en la Pontificia Universidad Católica de Chile. Ingeniero Industrial por la Universidad Nacional de Ingeniería, Perú.

Profesor en la Escuela de Postgrado de la Universidad del Pacífico y en la Escuela de Postgrados ESAN. También ha enseñado en Centrum Católica y en Escuela de Postgrado de la Universidad Peruana de Ciencias Aplicadas (UPC), Perú.

Ha sido Presidente del Encuentro Logístico Convención Minera (2009 y 2013) y Presidente de APPROLOG (Asociación Peruana de Profesionales en Logística) (2010-2012). Es investigador externo del Grupo de Investigación "Ética, Ambiente y Sociedad" del INTE-PUCP y miembro del Comité Consultivo de la Facultad de Ingeniería Industrial de la Universidad de Ingeniería (UNI).

Trabaja en el sector minero desde el año 1991 y desde el año 2000 en Antamina donde se desempeña como Gerente de Logística.

Correo: ealania@antamina.com 


\section{Introducción}

Es innegable la magnitud de los cambios que han sufrido los mercados y las organizaciones en los últimos años. La velocidad $\mathrm{y}$ agilidad con que se modifican las nuevas y variadas formas de competir, hacen de la competitividad y de la mejora continua un tema relevante para este contexto. Las relaciones entre empresas son una fuente importante de generación de ventajas competitivas, de creación o incremento de la innovación, y consecuentemente de una mejor rentabilidad (Prior 2011).

Según Porter (1991), a inicios de los años 90 la innovación o utilización de las ideas tiene un importante rol en la búsqueda de la ventaja competitiva; es una actividad para mantener la continuidad de una organización, aunque es notorio que muchas empresas no tienen la capacidad ni los recursos para lograrlo. Queda claro que los temas regulatorios y las fuerzas del mercado hacen y harán cada vez más necesario realizarla y promoverla. Además, las organizaciones tienen recursos limitados para innovar, por lo que incorporar otros actores a este esfuerzo incrementa su amplitud y posibilidades de éxito (Stewart y Fenn 2006), (Minguela-Rata et al. 2014), (Jaija et al. 2014), (Gallego et al. 2011), (Kim et al. 2015).

Así, el ratio de innovación es considerado como uno de los principales indicadores de la competitividad en la dinámica de las economías y aun cuando las innovaciones han estado enfocadas desde un punto de vista muy tradicional, se ha visto que tienen un impacto muy grande en el desarrollo de las economías; siendo su principal promotor Joseph Schumpeter, a quien el presente trabajo va a nombrar repetidas veces (Dabic et al. 2011).

Otro punto que hay que destacar es la importancia estratégica de la administración de la cadena de suministro o de la logística, la cual ha crecido exponencialmente en las últimas dos décadas, entendiendo por estratégicos a los elementos que pueden hacer posible la obtención de una ventaja competitiva o el incremento de la trascendencia de la actividades empresariales. Cuando se habla de transcendencia, se la relaciona con el cumplimiento de los objetivos empresariales que van más allá de la utilidad o de la ganancia fruto del propio negocio. Conocimiento, 
aprendizaje e innovación, deben ser entonces elementos clave para las organizaciones, de forma de generar nuevos circuitos virtuosos que alienten el desarrollo (López 2006).

Los análisis modernos respecto al crecimiento económico destacan el papel principal de la innovación, interiorizando en los factores que la favorecen e incluyendo variables cuantitativas y cualitativas. Hay que destacar el hecho de que si los diversos agentes económicos sienten que no son capaces de generar ni de aplicar innovaciones, estas no se generarán; debe existir un clima adecuado que la propicie (Galindo et al. 2012).

En la revisión efectuada sobre la innovación se identifica una brecha entre la percepción de innovación por parte de las empresas y los criterios requeridos según los investigadores para llevar a cabo una exitosa innovación. Este último punto revela la importancia que tiene estudiar el fenómeno desde ambas perspectivas (Dumay et al. 2013). No es sorprendente que la literatura sobre la cadena de suministro reconozca que esta deba ser tratada estratégicamente, siendo objeto de análisis para la creación de ventajas competitivas, incluyendo la posibilidad de hacer innovación. Tradicionalmente los proveedores han tenido un importante y directo impacto en el costo, en la calidad, en la agilidad y respuesta a sus empresas clientes; sin embargo, el nuevo ambiente competitivo existente requiere una reconsideración del papel de la cadena de suministro o de la logística (Lee y Kim 2009), (Johnston y Kristal 2008).

Con todos estos cambios en la función de abastecimiento, el papel del proveedor creció en importancia y se pusieron de relieve los instrumentos que relacionan al proveedor con el cliente tales como el contrato y las transacciones, elementos que están enmarcados dentro de la relación cliente-proveedor y constituyen dos de sus principales mecanismos. Así, una cercana relación entre el cliente y sus proveedores podría facilitar el trabajo y mejorar la eficiencia del producto o servicio, haciendo posibles esquemas de cooperación sobre la base de la generación de nuevas ideas (Kumar et al. 2003).

Administrar eficazmente la colaboración con los proveedores también pasa por armonizar diferentes estilos de dirección, integrar diferentes bases de conocimiento, y lograr un flujo eficiente y efectivo de información (Valle y Vásquez-Bustelo 2009). La cadena de suministro de las organizaciones tiene una serie de retos para las próximas décadas, tensiones que pasan por una adecuada selección de proveedores y administración de toda la cadena generada por la presión de grupos de interés que han incrementado el involucramiento en temas sociales y ambientales (Jensen et al. 2013).

Entonces, una cercana relación cliente-proveedor puede ser un elemento para impulsar la innovación durante el proceso de búsqueda de nuevas soluciones en el ámbito de manejo de las empresas, mejorando 
su posición competitiva dentro del mercado. En ambientes dinámicos, las empresas necesitan renovarse, expandirse y eventualmente redefinirse; así la innovación podría ser una condición clave para garantizar su supervivencia. Esta necesidad de desarrollarse y/o de diferenciarse de sus competidores, requiere del concurso de recursos (conocimientos y habilidades) dentro y fuera de la organización, principalmente de los proveedores de la misma (Minguela et al. 2014).

Las vinculaciones sociales de las empresas son ahora una realidad. No es posible desvincular a la empresa de su entorno y ya se puede advertir que en la estrategia organizacional está el componente social (Murphy y Poist 2002). Adicionalmente, un aspecto poco considerado tanto por los teóricos como por las empresas es la vinculación entre innovación y responsabilidad social.

No es objetivo de este trabajo interiorizar en el concepto de responsabilidad social, sino darle a la innovación, además del carácter tecnológico, consideraciones sociales. Resulta particularmente extraño que a quienes se ocupan de la innovación no les interesen los aspectos sociales, y que quienes estudian y piensan en la sociedad no comprendan la importancia que la innovación tiene a la hora de comprender las diferentes sociedades. Tampoco la Sociología, como ciencia que estudia a la sociedad y sus interrelaciones, ha hecho gran esfuerzo en profundizar en la relación entre la innovación y los entornos socio-culturales (Köhler y Gonzales 2014). Es así que la innovación no solo responde a necesidades empresariales u organizacionales, sino que es fundamentalmente un fenómeno social, que deriva de la sociedad y que regresa a ella, y que en una gran medida la posibilidad de innovar indica el grado de organización que tiene la sociedad y su capacidad para renovarse y mejorar.

Aun cuando la innovación es un fenómeno muy relevante para la sociedad, sea para las políticas públicas o para las prácticas empresariales, no recibe la atención adecuada, en buena parte debido al poco entendimiento que se tiene sobre el tema (Beristain 2009). Así, la innovación debe estudiarse como un proceso social, como la movilización de competencias colectivas y conocimientos compartidos no reducibles a un modelo mecanicista, de tal forma que las innovaciones tecnológicas tengan un decidido impacto social y puedan obligar a innovaciones institucionales (Köhler y Gonzales 2014), (Johannessen 2013). Estudios hechos en España, Italia y el Reino Unido sobre la relación entre la Responsabilidad Social Empresarial (RSE) e innovación, llegaron a la conclusión que ambos elementos se influencian (Gallego et al. 2011).

Es interesante puntualizar que empresas altamente innovadoras como Apple, Inditex (Zara) o Ikea, no son difíciles de seguir o de copiar; no siendo suficiente emular las organizaciones o reclutar a los talentos directivos de 
estas empresas. La fuerza innovadora y como consecuencia la capacidad competitiva, no residen en los conocimientos individuales, sino en una particular combinación y una forma de conocimiento colectivo, el cual es difícilmente repetible, aun cuando todos los elementos sean traslados a otro lugar u organización. Resulta entonces obvio afirmar que la innovación es ampliamente reconocida como un factor clave para asegurar una capacidad competitiva sostenible (Köhler y Gonzales 2014).

\section{Objetivo del estudio}

El presente estudio hace una revisión conceptual de lo que significa innovación en el ámbito de la logística o cadena de suministro (para efectos de este estudio se usan indistintamente ambos términos), y cómo se puede relacionar esta con aspectos sociales. Comprende una revisión de la literatura existente en aspectos específicos de la innovación y de la cadena de suministro, así como de las interrelaciones existentes entre cliente-proveedor que pudieran fortalecer el concepto y su aplicación.

Tomando como base la revisión efectuada, se propone un esquema de innovación aplicado a la cadena de suministro, que parte de una propuesta conceptual de posicionamiento de la innovación; así como la revisión de un caso en el cual se aplicó este esquema: en la Compañía Minera Antamina (empresa minera peruana), durante la ejecución de su programa Desarrollo de Proveedores de Excelencia.

Las preguntas que este trabajo intenta responder son:

- ¿Existe una vinculación entre el relacionamiento cliente-proveedor y la innovación? ¿Cómo se puede innovar desde los proveedores? ¿Cuál es la ganancia de proveedores y clientes en los esquemas de innovación conjunta?

- ¿Cuál es el verdadero papel de los proveedores y de los clientes en la innovación? ¿Tiene la innovación grupos de interés? ¿Cuáles son? ¿Cómo se relacionan?

Hay que precisar que no es objetivo del caso presentado, la relación directa de la innovación con los aspectos sociales de la misma. Sin embargo, es notorio que la asignación de recursos finitos de las empresas puede ser derivada a distintos intereses y socialmente, y dada la historia reciente en América Latina propiciada por los casos de sobornos liderados por Odebrecht y otras empresas brasileras, es infinitamente mejor disponer los escasos recursos en innovación, que en actos de corrupción, los cuales socavan las raíces buenas de cualquier sociedad. 
Por esta razón, se plantea una pregunta que no se intenta responder pero sí puede servir para reflexionar y dejar para otras investigaciones, su estudio y análisis.

¿La innovación social es un concepto aplicable a las empresas? ¿Cómo conciliar las necesidades de innovación operacional con los aspectos sociales de la innovación?

\section{Metodología empleada}

El presente estudio tiene un propósito descriptivo y exploratorio, por lo que se ha utilizado un enfoque cualitativo del caso seleccionado, para conocer y describir los aspectos vinculados con la innovación dentro de las relaciones cliente-proveedor.

El propósito de la investigación exploratorio-descriptiva está enfocado en identificar y describir las características de la innovación dentro de los aspectos de relación cliente-proveedor y explorar el impacto social que esta innovación pueda tener. El enfoque cualitativo ha sido utilizado por la siguientes razones: (a) este diseño se ha incrementado en investigaciones similares a la realizada y es más frecuente en los últimos años (Yin 2003); (b) el problema es de índole humano y social, dado que la innovación y las relaciones entre cliente-proveedor se materializan a través de las personas (Marshall y Rossman 1999); (c) la innovación es un tema de carácter nacional donde se tienen problemas de aplicación y de enfoque, por lo que estudiar el tema desde un caso representa más ventajas que desventajas.

No se han hecho investigaciones en el Perú que unan la relación cliente-proveedor con el desarrollo de esquemas de innovación. Lo que se han hecho son diagnósticos que detallan algunas acciones que las empresas deben tener en cuenta con los proveedores de manera de ser o no elegibles para ser contratados, sin embargo no mencionan temas de innovación o de creación de conocimiento como resultado de la relación (Marquina 2011). El presente trabajo muestra cómo la actividad logística puede ser clave para la consecución de los objetivos de las empresas en su potencialidad innovadora, con el beneficio que eso trae consigo.

\section{Revisión de la literatura}

\subsection{Innovación}

Al tratar la innovación hay que referirse de primera intención a Say (1803), quien conceptualizaba el término al indicar que la acción de reasignar recursos 
con nuevas formas de producir riqueza era una innovación. No se puede crear la materia, pero si se puede crear su utilidad, aumentar o disminuirla (Beristain 2009). Otra definición es la Schumpeter, quien la enmarcó como los cambios en la combinación de los factores de producción que no pueden ser afectados por infinitesimales pasos o variaciones en el margen. Así, la innovación se considera una fuerza desequilibrante del sistema económico, haciendo las distinciones entre el avance científico, la invención técnica y ambos de la innovación propiamente dicha. El avance científico es el que se preocupa de las explicaciones generales a un fenómeno, mientras la invención técnica es una solución original como resultado de la síntesis de información acerca de los medios técnicos por los cuales se puede satisfacer (Beristain, 2009). La innovación es ya un fenómeno económico social de reajuste de los recursos y de búsqueda del crecimiento y desarrollo, al desarrollar e introducir en el mercado, productos o formas nuevas de hacer las mismas cosas y que mejoran la calidad de vida de la sociedad.

Hoy en día, se ha acuñado el concepto innovación social que alude a nuevas ideas, productos y servicios que atienden simultáneamente a las necesidades sociales y crean nuevas. Así, la innovación social es un concepto multidimensional: económico, cultural, social y tecnológico, en el que se entrecruzan diversos agentes (Köhler y Gonzales 2014).

Los estudios sobre innovación y cambio social definen cinco momentos de cambio en el sentido técnico-económico: (1) la revolución mecánica del vapor aplicada al sector textil entre 1770 y 1830; (2) la extensión de esta tecnología a otras actividades como el ferrocarril entre 1830 y 1890; (3) el descubrimiento de la electricidad y el desarrollo de la industria pesada entre 1890 y 1930; (4) la extensión y crisis de la lógica de producción en masa entre 1930 y 1980; y finalmente (5) la irrupción de la revolución digital y de las comunicaciones. Todos estos cambios tecnológicos acarrearon también cambios políticos y sociales (Köhler y Gonzales 2014).

Una manera de diferenciar las innovaciones, es clasificarlas en dos grandes grupos. De un lado, las innovaciones sostenibles e incrementales, que son las que suelen ser desarrolladas e introducidas por las empresas, generalmente grandes, ya establecidas; y de otro lado, las innovaciones de ruptura, que se identifican con el espíritu emprendedor de personas y/o empresas que irrumpen en el mercado.

No se puede negar que el grado de concentración, las barreras a la entrada en los mercados, así como el tamaño de demanda presente o potencial, afectan al fenómeno de la innovación de manera importante. Algunos investigadores, se refieren a una tercera categoría, la que llaman de evolución y que catalogan como de movimiento continuo, más acorde con la participación de la empresa en lugar del agente emprendedor (Dumay et al. 2013). 
Es oportuno recalcar que la innovación no solo se refiere a cambios en la tecnología, sino a nueva rutinas, tanto administrativas como productivas, y de nuevos arreglos organizacionales, que alteran los costos de coordinación productiva y de uso del mercado, tal como en los 80 lo explicara Williamson al hablar de la Teoría de los Costos de Transacción (TCT).

Un tema relevante en la TCT es lo que se denomina el Oportunismo Contractual Hold-up Problem de acuerdo a la versión original de Williamson, que en términos resumidos significa que las partes se defienden de posibles escenarios futuros, donde alguna de estas pudiera tomar ventaja. En el caso de la innovación, es innegable que la innovación aplicada produce beneficios por lo que los mecanismos de apropiación de los beneficios (entre comprador y vendedor), comerciales o de propiedad intelectual, deben estar claramente determinados; si no es así, esto desincentivaría la propia innovación:

Dada la explicación anterior, es comprensible afirmar que sería la organización empresarial y no la persona emprendedora el agente económico en mejor capacidad para innovar o para propiciar la innovación. Esto último conlleva a afirmar que la innovación se difunde por efecto y acción de la empresa — cuando más grande más difusión- que por la acción del propio emprendedor.

Una relación cliente-proveedor provechosa ayuda a que crezca la confianza entre proveedores y clientes. Esa confianza, que se traduce en menor oportunismo contractual, ayuda a disminuir los costos de transacción. La innovación que vincule a proveedores y clientes requiere de un ambiente de confianza que pueda lograr innovación y fruto de ella, ventajas competitivas para ambos.

Si el mejor agente innovador es la empresa, resulta más o menos obvio que es la gran empresa la que tendrá las mejores posibilidades de hacer o de favorecer la innovación, aunque eso no sea razón suficiente para conseguir un esquema de innovación exitoso. Autores como Teece (2016) refieren que debe tenerse un diseño apropiado, el cual tiene cuatro dimensiones: (1) estructura de la organización, (2) dotación y desarrollo del capital humano, (3) conformación de una red de vínculos hacia el exterior de la organización, y (4) la cultura y los valores de la organización que favorecerán un clima de apertura, ensayo y confianza, indispensables para la innovación.

La innovación no es ajena al lugar donde se genera, por lo que se puede afirmar que la innovación es resultado de la acción social interactiva entre los diferentes actores involucrados orientados a la generación de nuevos conocimientos. El enfoque teórico sobre la innovación no fue muy desarrollado y así entonces su estudio siguió la misma suerte. 
En un informe de la Oficina de Investigación Científica y de Desarrollo de los Estados Unidos publicado en 1945 se establece la interpretación ortodoxa de la secuencia de la innovación, que considera un modelo lineal de cascada según el cual se empieza en la investigación científica, se transfiere a la investigación aplicada, de lo que resulta en un nuevo producto que es elaborado industrialmente luego de haber hecho los estudios de mercadeo correspondientes para pronosticar su ingreso exitoso en el mercado. Este esquema lineal y secuencial se mantiene hasta ahora según los modelos de gestión de la innovación gerencial, los cuales ofrecen herramientas de gestión para cada una de estas fases (Köhler y Gonzales 2014).

La innovación es un proceso social que tiene su origen en el interior de las organizaciones. Schumpeter señala que la innovación científica no es necesariamente el principio en la secuencia propia de la innovación y que tiene un papel secundario frente a la innovación aplicada llevada a cabo al interior de las organizaciones, poniendo de relieve que el principal agente innovador se encuentra dentro de las mismas organizaciones y no fuera de ellas. Así la innovación no resulta o no debe resultar de la caza de beneficios monopolistas por parte de la empresa u organización, o de la institucionalización de la investigación y desarrollo de las grandes corporaciones, sino de la interacción positiva de los actores del proceso de generación de valor al interior mismo de las organizaciones.

La función esencial de una la empresa no es la adquisición de conocimientos explícitos y codificados, sino la generación y transmisión de conocimientos tácitos que no se pueden adquirir en el mercado y que son difícilmente reproducibles por los competidores (Köhler y Gonzales 2014).

Se ha hecho mención a los aportes referidos a la innovación que Schumpeter publicó en la primera mitad del siglo XX. Schumpeter fue un economista de origen austriaco, reconocido por sus contribuciones al hecho de poner de relieve la importancia de la creación de nuevas empresas y del espíritu emprendedor para la creación del bienestar y de mejora de la calidad de vida.

Entre los conceptos desarrollados por Schumpeter, tenemos el de la destrucción creativa, el cual describe el proceso de transformación que acompaña a la innovación. Es comprensible que Schumpeter partiera de teorías ya existentes de A. Smith, D. Ricardo, K. Marx entre los principales, tanto para reconocer que hasta el día de hoy, una pregunta común de investigación es si Schumpeter era marxista o no.

La distinción entre Marx y Schumpeter es simple y totalmente diferenciadora, el no uso del elemento central de las clases sociales, como no creer que el desarrollo del capitalismo devendría inevitablemente en el colapso económico, sino más bien, en reforzar la figura del emprendedor como figura de quiebre y desarrollo, hace que ambos pensadores se diferencien de raíz. Habría que puntualizar sin embargo, que no existe en la teoría un 
antagonismo entre emprendedores y trabajadores y quizá, esa es la razón de asignar a Schumpeter una concordancia mayor con el pensamiento de Marx. Tenemos entonces, que el desenvolvimiento económico es un fenómeno puramente económico y se manifiesta por las rupturas del equilibrio, que como ya se indicó, se devino en llamar destrucción creativa (Galambos 2011), (Kurtz 2012), (Yoguel et al. 2013).

El concepto de destrucción creativa fue introducido por Schumpeter en 1942 en su libro Capitalismo, Socialismo y Democracia. Con este concepto se describe el proceso de innovación que tiene lugar en la economía de mercado en el que los nuevos productos destruyen viejas empresas y modelos de negocio. Para Schumpeter, las innovaciones son la fuerza detrás del crecimiento económico sostenido a largo plazo, pese a que se pueda destruir en el camino el valor de compañías bien establecidas; y este proceso es el hecho esencial del capitalismo, siendo su protagonista central el emprendedor innovador. La destrucción creativa da lugar a nuevas combinaciones y por ende a una mayor variedad de productos que son ofrecidos a su vez por una variedad de organizaciones, que compiten no solo en esos productos, sino también en métodos de producción y formas organizacionales. Este proceso es impulsado por los agentes creativos que van contra las reglas imperantes. En la propia construcción del concepto se puede observar cómo las innovadoras combinaciones que se piensan generan nuevas empresas y migran a empresas grandes para proteger, hasta donde sea posible, las nuevas combinaciones de la entrada de nuevos competidores.

Schumpeter también critica la competencia basada en los precios e indica que la competencia relevante es la que se da en la calidad y en los costos, donde una condición necesaria para que se dé y genere el desequilibrio que lleva al progreso es la libre entrada de nuevos emprendedores. Esto concuerda con la preocupación de diferenciar la innovación de la aplicación, ya que se requieren no solo invenciones, sino que estas se transformen en aplicaciones (Yoguel et al. 2013).

Los caminos para innovar según Schumpeter son: (1) introducción de nuevos bienes o de bienes de nueva calidad; (2) introducción de un nuevo método productivo; (3) apertura de un nuevo mercado; (4) nuevas fuentes de oferta de materias primas; y (5) establecimiento de una nueva organización.

Ahora bien, la idea de la organización como un fenómeno sistémico, más allá de solo el espíritu emprendedor, si bien fue sugerida por Schumpeter, tiene una elaboración mucho más reciente, cobrando especial importancia toda la superestructura institucional que rodea o debe rodear al fenómeno de la innovación (Yoguel et al. 2013).

Schumpeter fue un estudioso de la historia económica para el que muchos de los errores en el análisis económico se deben a la ausencia de entendimiento histórico, así como a la falta de competencias en campos 
como la antropología o la etnología, y hacía notar que un científico económico debería ser competente en tres técnicas: historia económica, teoría económica y estadística, a las que añadió luego una cuarta técnica, la sociología económica. La primera razón era que tenía ventajas pedagógicas, pues es difícil entender los fenómenos si es que no se conocen, aunque ello pueda ser discutible o equivocado, lo que ya se había estudiado de este; la segunda razón es ver la pertinencia de lo aseverado sobre lo estudiado de las viejas teorías; la tercera razón es que la historia nos puede dar entendimientos de la lógica usada y así nutrir nuestra lógica; la cuarta y última razón es que la economía tiene un proceso histórico único.

Una de las conclusiones más importantes de sus primeros estudios fue que el capitalismo era un proceso en evolución y que ese hecho era fundamental para explicar todos los problemas económicos; la segunda conclusión es que la evolución en sí no era propia de los efectos externos sino de una especie de mutación económica, que es como se denomina a la innovación. Lo anterior es de importancia en ambos puntos, pero se resalta de manera preliminar el carácter muy relevante que tiene para Schumpeter la innovación en el desarrollo económico y en la evolución del sistema.

Adicionalmente, Schumpeter cree que los procesos de producción son una combinación de fuerzas productivas compuesta por los factores originales de producción así como de otros intangibles, fundamentalmente el conocimiento y la innovación. (Bögenhold 2014), (Kurtakko 2014).

Hay que puntualizar que el papel de la demanda o de los compradores en la dinámica de la innovación está ausente en la obra de Schumpeter, como en la mayoría de estudios sobre la innovación, resaltando con mucha preponderancia el papel de la empresa innovadora y dejando de lado el papel del objeto de la innovación, el usuario de la misma.

Uno de los teóricos de la demanda como propulsor de la innovación es Saviotti (2008), quien desarrolla una idea del crecimiento económico y cambio estructural basada en la saturación de la demanda de viejos mercados y la creación de nuevos sectores, en los que el aumento de la variedad es condición necesaria para el desarrollo de largo plazo.

Se ha mencionado anteriormente la innovación institucional. Es cierto que las innovaciones tecnológicas hacen pensar en nuevos esquemas o sistemas institucionales, los cuales administran en la práctica la creación de valor y controlan su impacto. Estas innovaciones institucionales pueden ser clasificadas en innovaciones políticas, culturales y sociales. Las políticas aquí se refieren al poder y la ideología, las culturales a los valores y normas aceptadas por el grupo social, y las sociales a las relaciones entre los diferentes miembros de la sociedad. Temas como las redes sociales, la participación de la empresa en temas relativos al gobierno, o cambios en la manejo de medios o redes sociales, son claros ejemplos de esto último (Johannessen 2013). 
La potencialidad del comprador puede ser una pieza clave en la generación de innovación, debiendo esta última llevarse a cabo dentro del marco de la relación cliente-proveedor.

\subsection{Relación cliente - proveedor}

El papel del área de abastecimientos ha evolucionado constantemente dentro de las empresas. Investigadores de la empresa como de las universidades lo han puntualizado (Ageron et al. 2013), encontrándose varios trabajos que sugieren un cambio en su rol, de un nivel operativo a uno estratégico. Más adelante se mencionarán detalles, pero de momento se desea resaltar de manera especial dos trabajos: el de Kraljic (1983) y el de Ellram y Carr (1994). Kraljic, hizo notar los nuevos elementos que se tienen en la realidad económica mundial y la unión de la estrategia en abastecimientos y el tipo de materiales, según su costo y su importancia en la generación de utilidades. Como la actividad comercial creció sostenidamente en todas las regiones del planeta desplazando las fronteras nacionales, la investigación sobre la administración de proveedores en diferentes contextos culturales proveyó información útil para la gerencia. Por ello es cada vez más frecuente ver estudios sobre las relaciones cliente-proveedor en áreas geográficas o de firmas fuera de los Estados Unidos o el Japón (Wasti et al. 2006); también los mercados se han convertido en más competitivos y más transparentes. Se necesita entonces que los proveedores tengan controles adicionales sobre los recursos empleados, buscando reforzar la competitividad (Sternquist et al. 2008).

El otro trabajo relevante es el de Ellram y Carr (1994), en el que se hizo una revisión literaria de lo que significó el abastecimiento estratégico. En este estudio, los autores hicieron un recuento de trabajos sobre el papel estratégico del abastecimiento de materiales, en donde refirieron investigaciones que resaltan este componente. Se revisó el desarrollo de la función de abastecimientos hacia el nivel estratégico y en donde se fundamenta la integración del área de abastecimientos a este nivel. Es interesante destacar que en este punto la concentración de los trabajos sobre el rol estratégico de abastecimientos en las empresas no es reciente, sino de los años 80 o 90, lo que indica que en la actualidad ya pocos cuestionan su papel estratégico. En trabajos recientes se ha discutido acerca de las estrategias futuras en abastecimientos y en donde ya no se hace necesario justificar el cambio de nivel de la función de abastecimientos.

También se ha afirmado que la demanda incrementada por una competencia global ha soportado de manera muy fuerte la necesidad de cambiar la forma de relacionarse con los proveedores, incorporándolos en algunos procesos internos a fin de facilitar el flujo de información para la eficiente producción de bienes y servicios. Es preciso señalar que las relaciones 
entre cliente y proveedor, como cualquier otra relación, son complicadas, por lo que desarrollarla de manera positiva es esencial para poder compartir información dentro de las unidades de negocio de la empresa, siendo las interrelaciones internas y las interrelaciones con los clientes, los principales focos de atención para un soporte eficiente al mercado (Lee et al. 2007).

Muchas organizaciones buscan acuerdos con otras organizaciones (proveedores) para responder de manera rápida a los cambios en las tecnologías y al ambiente competitivo desde las capacidades de estas otras organizaciones, las cuales refuerzan las estrategias de cooperación y colaboración (Soosay et al. 2008).

En el caso de las interrelaciones con los proveedores, el punto central deben ser los proveedores más importantes de materiales o servicios críticos, a los cuales hay que involucrar en el diseño de nuevos productos, en el planeamiento de producción y en el manejo de inventarios, desarrollando una respuesta rápida a las necesidades cambiantes del mercado sobre la base de la red de proveedores que aseguran los suministros en fechas y calidad confiables, intercambiando a su vez información con los proveedores para hacer el proceso eficiente (Lee et al. 2007).

También el involucramiento de los proveedores en el desarrollo de nuevos productos e innovaciones técnicas en industrias como la automotriz, ha crecido en importancia los últimos años. Asumir responsabilidades en el diseño y calidad ha sido lo más característico, sin embargo, su participación en otros aspectos, como los sociales y ambientales no ha sido examinada con profundidad (Geffen y Rothenberg 2000).

Ahora bien, la literatura sobre innovación en la cadena de suministro principalmente ha estado dirigida hasta hoy, a la participación de los proveedores en el desarrollo de nuevos productos por sus clientes, teniendo un rol de soporte y/o apoyo en estas innovaciones (Ageron et al. 2013).

La administración de las relaciones cliente-proveedor es un tema central en el éxito de la cadena de suministro de cualquier empresa. Las relaciones de orden estratégico con los proveedores críticos deben ser entendidas en su correcta dimensión y potencialidad de creación de valor (Ambrose et al. 2010). Las relaciones cliente-proveedor han sido estudiadas por varios autores desde diversos ángulos, siendo importante para establecer un marco conceptual integrado, revisar la literatura sobre el particular.

Los modelos encontrados acerca de la relación con proveedores son en orden cronológico los siguientes: Kisser (1976), Ford (1980), Hakansson (1982), Campbell (1983), Williamson (1985), More (1986), Dwyer, Schurr y Oh (1987), Landeros y Monczka (1989), Helper (1991), Evans y Laskin (1994), Dion, Easterling y Miller (1995), Groves y Valsamakis (1995), Monczka, Callahan y Nichols (1995), Leuthesser (1997), Gadde y Snehota (2000) y Cox, Lonsdale, Watson y Qiao (2003). Solo se ha podido tomar nota del modelo de 
More, en el que se detalla sobre innovación y el modelo de Cox, que es el más comprehensivo de todos y en el que se desarrollan los mecanismos y objetos de la colaboración.

More (1986) propuso un modelo genérico para la relación entre proveedor-cliente en el desarrollo de nuevos productos o en la adopción de nuevos procedimientos. El modelo tiene tres sub-procesos: desarrollo, adopción e inter-fase. El modelo de More fue muy limitado y no aplicable a otras situaciones entre proveedor y cliente (Lau y Goh 2005; More 1986).

Cox, Lonsdale, Watson y Qiao (2003) desarrollaron un modelo de los tipos de relación cliente-proveedor que combina dos factores, la manera de trabajar y el reparto del excedente creado en la relación. Se tienen dos maneras de trabajar, de enfrentamiento y de colaboración; existen, a su vez, tres formas de repartir el excedente, sesgado al cliente, sesgado al proveedor o balanceado; y se generan seis tipos de relación: de enfrentamiento sesgada hacia el proveedor o cliente, de colaboración sesgada hacia el proveedor o cliente, y balanceada de enfrentamiento o de colaboración.

Cox indicó que una buena relación cliente-proveedor no es una buena práctica para todos los casos y lo es solo en determinadas circunstancias. Este modelo ayuda a entender cómo se generan mecanismos de confianza derivados de la relación cliente-proveedor. Esto es importante ya que la innovación solo podrá darse en un ambiente de confianza entre el cliente y el proveedor (Cox et al. 2003).

La brecha que se muestra en la literatura es que en todos los modelos presentados no existe uno que afirme con precisión cuándo es bueno aplicar una estrategia de colaboración, qué significa ello realmente y cuándo no es necesario tenerla y propender a una estrategia de enfrentamiento. Tampoco existe algún modelo de relacionamiento con los proveedores, que se ocupe de la innovación como tema económico social, buscando integrar aspectos competitivos internos de la empresa con aspectos competitivos de la sociedad. Hay que puntualizar que las relaciones cooperativas tienden a establecer relaciones de largo plazo, basadas en el establecimiento de objetivos comunes y un balance para los beneficios y para los riesgos (Canto et al. 2009).

Un elemento importante de la administración de la relación cliente-proveedor son los contratos, los cuales por definición práctica son incompletos, dado que es imposible contemplar todas las variables futuras, así ningún contrato que se elabore para el futuro, será completo (Schmitz 2001). Dentro de la estructura contractual se tiene el manejo del comportamiento oportunista que ocurre cuando se dan dos factores: (a) cuando las partes deben hacer inversiones en activos específicos antes de la transacción propiamente dicha en orden de estar preparados para la misma, y (b) cuando la óptima transacción no puede ser prevista en su totalidad de forma ex-ante y eso depende del comportamiento posterior. 
En aspectos tan sensibles como el conocimiento como elemento diferenciador, es necesario contemplar mecanismos de protección que puedan lograr un ambiente en donde sea posible la generación y prueba de nuevas ideas (Rogerson 1991). En este punto y dada la complejidad e imposibilidad de tener contratos completos, algunos proponen tener contratos simples en donde ex-ante se presumen renegociaciones posteriores. Así, ante la perspectiva ideal de tener un contrato completo, aunque esto sea una imposibilidad real, las partes pueden anticipar una renegociación y ponerlo desde el contrato inicial (Schmitz 2001). También las previsibles diferencias futuras por eventualidades o situaciones no contempladas, hace que sean importantes en los contratos de largo plazo, el manejo y la mecánica para las futuras renegociaciones (Lülfesmann 2001), (Hirakubo et al. 2015).

Parte importante de la relación cliente-proveedor es la creación de confianza. Se puede decir que confianza es un estado en el que existen expectativas positivas acerca de las motivaciones de la contraparte en situaciones de riesgo que comprometan la relación (Jeffries y Reed 2000). Dimensiones de la relación cliente-proveedor, tales como confianza y compromiso, juegan un rol muy importante en la creación de valor estratégico, en particular cuando se requieren inversiones específicas y la gobernanza contractual es complicada (Ambrose et al. 2010), (Prior 2011).

En las relaciones colaborativas con foco en la innovación, las investigaciones recalcan las limitaciones, debido al retorno esperado por ambos, comprador y proveedor, de los beneficios del esfuerzo por innovar, pero no hay mejor manera de trabajar de forma conjunta que con esta clase de objetivos (Kim et al. 2015). Las personas, en el contexto de las organizaciones frecuentemente están expuestas a riesgos e incertidumbres en sus relaciones interpersonales. Para mitigar esos problemas, los individuos y las organizaciones crean estructuras formales como jerarquías, regulaciones y contratos, así como también estructuras informales como costumbres, normas y confianza. Dentro de estos mecanismos, el uso de contratos es el que más prevalece, además de ser quizás el más persuasivo.

En las organizaciones, los contratos han podido en buena medida solucionar los problemas rutinarios. Así entre organizaciones, los contratos ponen los términos de una alianza cliente-proveedor, entre otros. En este contexto, los contratos facilitan el intercambio por la reducción en la incertidumbre y con alguna frecuencia hacen que las partes creen relaciones de mutuo beneficio. Aun cuando los contratos pudieran ser necesarios, la cooperación entre empresas, en este caso cliente-proveedor, puede ser alcanzada sin estos (se entiende contratos formales).

Los mecanismos informales tales como la confianza pueden ayudar a resolver los problemas que se presenten, facilitar los procesos de negocio e incrementar la cooperación entre las organizaciones, mejorar la comunicación 
y por ende lograr negociaciones más eficientes al reducir el tiempo para lograr acuerdos. Se puede decir que una mezcla de estructuras formales e informales es indispensable para el manejo de relaciones complejas, como las de clienteproveedor en un mundo competitivo y globalizado (Malhotra y Murnighan 2002).

Para el establecimiento de esquemas de innovación dependientes cliente-proveedor, el aspecto de confianza es sustancial y es parte de la misma innovación tanto del cliente hacia el proveedor como viceversa, ya que implica cambios en los mecanismos de relacionamiento, sean estos mecanismos formales o relacionales. La innovación es uno de los mayores y mejores resultados de la relación cliente-proveedor. Estrechas y cercanas relaciones entre clientes y proveedores, facilitan el desarrollo de nuevas ideas y su posterior aplicación a un producto y a su comercialización (Prior 2011).

Desde el punto de vista del proveedor, se puede decir que el cliente es siempre un co-productor (Hansen 2009). La colaboración es útil si las partes tienen el objetivo común de innovar. En este punto las alianzas estratégicas son beneficiosas en la búsqueda de esa innovación tecnológica ya que complementa los recursos, tanto del cliente como del proveedor (Soosay et al. 2008).

Estaría claro que cultivar y mantener relaciones provechosas entre proveedores y clientes no es tarea sencilla. Proveedor y cliente requieren invertir recursos y capital frecuentemente por un largo periodo de tiempo en el que normalmente una de las partes involucra a la otra para buscar una relación exitosa; consecuentemente, no pueden ni deben tener relaciones de colaboración cercana con todos sus proveedores o clientes. De hecho, los esfuerzos de colaboración deben estar enfocados solamente en los proveedores de materiales o servicios estratégicos o con los que se compran grandes cantidades (Drake y Schlachter 2007).

La mayoría de las transacciones de negocios ocurre bajo una estrategia de enfrentamiento en la cual el comprador escoge al proveedor en un horizonte de corto plazo, basado en una combinación de costo y calidad. En este caso se tiene una pequeña colaboración entre las partes, especialmente porque el proveedor conoce que le serán solicitadas cotizaciones para compras en un corto periodo de tiempo (Drake y Schlachter 2007). Dado ese esquema natural de enfrentamiento, hacer innovación conjunta o dependiente es un reto interesante para las empresas.

Los proveedores forman parte de lo que se ha convenido llamar la cadena de suministro, concepto que se ha desarrollado en los últimos veinticinco años, precisando que los empresas que participan en hacer que los productos lleguen desde el proveedor hasta el cliente forman una cadena, en donde cada actividad y/o empresa es importante y en donde la fortaleza de la cadena será la fortaleza del eslabón más débil. Desde el artículo de Kraljic 
(1983), en donde desde el título se menciona la transición del concepto de compras al concepto de cadena de suministro, se precisó que hay que buscar la eficiencia en todos los eslabones de la cadena para garantizar la eficiencia del conjunto. Uno de esos eslabones es el de los proveedores.

Sandberg (2005) estableció en un estudio realizado en Suecia, tres interesantes hallazgos que son, al mismo tiempo, las tres mayores contribuciones de su investigación. La primera fue que es clara la relación entre la intensidad de la colaboración y los efectos positivos de la misma. La segunda, que la alta gerencia de las empresas constituye un importante conductor de la intensidad en la colaboración de la relación cliente-proveedor. El tercer hallazgo es que encontró, en el tema de la relación cliente-proveedor, grandes diferencias entre la teoría y la práctica.

En esta investigación y en relación con el tercer hallazgo, se concluyó que la colaboración se encuentra en los niveles operativos mas no en los niveles estratégicos, estando la innovación en este nivel. La colaboración basada solo en el nivel operativo, no puede trascender y llevar a una integración completa y útil, lo que se consigue solamente si el tema estratégico está involucrado en la relación cliente-proveedor. La ausencia de esta visión estratégica en la colaboración resultó en serias diferencias en las actitudes y comportamientos tanto del proveedor como del cliente (Sandberg 2005).

Otro factor que puede afectar las relaciones cliente-proveedor es el oportunismo, contractual o no contractual, dado que está implícito en ello el tema de la confianza y esta es clave para cimentar relaciones duraderas y positivas entre proveedor-cliente. La confianza representa un mecanismo importante de gobierno de la relación que mitiga los riesgos. La confianza está en las personas y es asociada con la vulnerabilidad y puede ser descrita como un estado psicológico que se basa en las expectativas positivas que tiene una persona sobre el comportamiento de otra.

Esta definición se puede transferir al ámbito de las empresas y en este sentido la confianza es la expectativa positiva y cierta del comportamiento de la contraparte, desarrollado como resultado de la experiencia de la propia interacción, sea esta de manera directa o indirecta. La interacción consiste en numerosos episodios de corto plazo de contacto interpersonal entre los gerentes de las compañías u otras personas de contacto. Esta experiencia repetitiva es la que define el grado de confianza entre las partes (Canning y Hanmer-Lloyd 2007).

Escoger confiar sobre la base del conocimiento de evidencias del comportamiento de la contraparte, es racional y por ende elegir confiar es algo esperado. Las dimensiones de la confianza son la percepción de credibilidad y benevolencia, entendida como la condición de actuar con buena voluntad. La primera dimensión es la credibilidad objetiva, basada en la integridad de las personas de la otra parte, las cuales mantienen sus compromisos, sean estos 
escritos o hablados. La segunda indica el genuino interés de una parte por la otra, lo que lo motiva a buscar el beneficio conjunto, recalcándose que esto es interpersonal y creado por las numerosas interacciones que se tienen entre proveedor y cliente (Canning y Hanmer-Lloyd 2007). Está claro que esquemas de innovación con los proveedores requieren el más alto grado de confianza entre ambos.

Para la relación cliente-proveedor hay que generar confianza entre ambos. La confianza creada entre las organizaciones tiene una importante toma de riesgos, tanto para el cliente como para el proveedor, sea porque se eliminan otras fuentes de suministro, se trabaja en la integración de procesos, se colabora en el diseño de los actuales, o de nuevos productos, entre otras cosas que incrementan los potenciales beneficios de la relación (Drake y Schlachter 2007).

Existen múltiples variables que influencian para tener una orientación de largo plazo, una de las cuales es el tamaño de la compañía compradora. El propósito de lograr un clima de confianza en la relación y un fluido intercambio de información es afectado por este tamaño, que es considerado un elemento importante para la relación. La tecnología, la estructura de estas compañías y la estrategia tanto del proveedor como del cliente hacia la relación con su contraparte, los objetivos y las experiencias anteriores de las personas que toman decisiones por parte de las compañías involucradas, también pueden afectar la relación.

Es claro que el tamaño de la empresa compradora, sea este grande o pequeño, puede determinar el nivel de poder y dependencia en la relación con los proveedores, que unido con el tipo de necesidades, las características de los productos o servicios a comprar y la estructura del mercado, podrían complicar un adecuado proceso de adquisiciones (Polo y Cambra 2007).

Una relación entre dos entidades, en este caso el cliente y el proveedor, solo puede existir si es que ambas perciben beneficios de la misma, ya que cuando la percepción de estos beneficios cesa, cada parte buscará su propio beneficio, sin la inversión de ningún recurso adicional en esta relación (Drake y Schlachter 2007).

Canning y Hanmer-Lloyd (2007) investigaron la creación de confianza en la relación cliente-proveedor. Para el estudio del comportamiento entre empresas asociado con la confianza y la adaptación, es importante tomar en cuenta el contexto de historia en términos de pensar en el largo plazo. Estos autores seleccionaron el estudio de caso para entender apropiadamente el problema de confianza y de un ambiente de adaptación dado el carácter de realidad que tienen las relaciones de intercambio. El estudio de caso se adaptó mejor que otras metodologías a los propósitos de esta investigación, que quiso tomar nota de las diferencias de la relación cliente-proveedor y de cómo son significativas las adaptaciones que las compañías realizan (Canning y HanmerLloyd 2007). 
Al parecer es claro que la relación de cooperación con los proveedores es una tendencia actual y futura de la posibilidad de lograr beneficios y en ese sentido es una buena práctica y así ha quedado establecido en estudios para conocer los pronósticos sobre las tendencias futuras en abastecimientos (Ogden et al. 2005). Desde la perspectiva de los proveedores, un trabajo cercano con sus clientes, en aspectos tecnológicos y de procesos, construye una relación más estrecha e incrementa los niveles de innovación. Así, las innovaciones en los sistemas y tecnología de la información desarrolladas en conjunto, mejoran la eficiencia operacional y el nivel de servicio de ambos, profundizando la relación (Geffen y Rothenberg 2000), (Ageron et al. 2013).

Es clara también la brecha en la teoría acerca de la aplicación de los modelos para relaciones entre clientes y proveedores y es más clara aún la brecha en la aplicación de estos modelos en la práctica de las organizaciones. El presente estudio tiene una mirada exploratoria de esquemas de innovación como parte de las relaciones cliente-proveedor, además de una presentación descriptiva de un caso en la industria minera peruana.

\section{Innovación desde la demanda: el papel del comprador. Modelo propuesto}

Los negocios actuales entre compradores y vendedores tienen ciertas dinámicas establecidas. Es cierto que el mensaje ha cambiado y ahora ya no se dice que están en las antípodas, pero los esquemas de colaboración son, por decir lo menos, poco comprensibles. Resulta obvio que si alguien vende algo es porque le conviene y si alguien lo compra también, pero entre esto y que resulte ser una relación de colaboración hay una distancia sideral. Es en este punto donde pueden ocurrir diferencias entre lo que se dice que se va a hacer y lo que al final se hace. De un comprador no valen sus opiniones, sino sus comportamientos. Se podría decir que es igual en el caso del vendedor, pero este trabajo se está haciendo desde la perspectiva del comprador y de su posible influencia en el comportamiento del vendedor, más allá de la transacción o de la relación con el comprador. ¿Quién tiene más influencia sobre los otros, el vendedor sobre el comprador o el comprador sobre el vendedor? No es propósito de este trabajo responder esta pregunta, pero sí partir de la premisa que el comprador puede y debe ejercer influencia sobre sus proveedores.

¿Qué puede relacionar a un cliente con un proveedor? La respuesta obvia es la utilidad, sea la de vender o la que se busca obtener al comprar. ¿Pudiera existir alguna otra razón? Podrían existir varias, como imagen de la marca, confianza en los productos, posicionamiento en el mercado, entre otras. Al 
final, todas estas se resumen en una utilidad actual o futura circunscrita solo al ámbito de la propia empresa.

Podrían existir otras razones cuando uno de ellos se adhiere a programas o campañas del otro. En este punto se piensa en programas de Responsabilidad Social Empresarial (RSE), que podrían pasar desde fines filantrópicos hasta programas mucho más elaborados contra el cambio climático o cuestiones por el estilo. Ciertamente, estos esfuerzos dependerán de las circunstancias y de los directivos y por sobre todo, de que se sigan estableciendo las relaciones de negocio entre compradores y proveedores.

En términos ideales sería óptimo pensar que el vendedor mantenga su participación en los programas de RSE, independiente de la relación de negocios y que al comprador solo hay que ayudarlo a dar el primer paso. No se tiene información, pero se presume que en pocos casos las empresas mantienen la ayuda a los programas de sus clientes independientemente de si se mantienen como sus proveedores.

Otro tema de relacionamiento que pudiera tener mayor viso de permanencia es la innovación. Si un cliente tiene un programa de innovación que parte de los proveedores, mantener la relación será la garantía de buscarla. Resulta obvio pensar que en los productos donde hay más competidores se margine menos que en donde no hay competidores, y aunque esta ausencia de competidores sea de tiempo limitado, es durante dicho tiempo que se marginaría más. Esta mayor marginación se daría con el resto de clientes y no con el que ha ayudado a establecer la innovación (nuevo producto).

Se ha establecido con abundancia de detalles el concepto de innovación y todo lo que está detrás, y está claro que la innovación involucra una serie de temas y no solo al producto innovador. Está claro también que se pueden tener muchas invenciones, pero si estas no se materializan o se buscan aplicaciones, deviene en poco útil a la sociedad. Es notorio que en el Perú hay poco de innovación y que por lo tanto no existe un sistema, formal o no, que busque o propicie la innovación. Si es obvio que los productos innovadores marginan más, porque entonces no se innova. ¿Cuáles serían las razones por las que no se innova? Aunque no es propósito del trabajo encontrarlas, algunas de ellas son fáciles de intuir: no hay mercado, no hay oportunidad, no hay escala, no hay recursos sean estos financieros o técnicos.

En este punto, un gran comprador tiene algunos caminos:

a) Uno compra productos, compra los mejores para sus operaciones y si no hay recursos internos para innovar, se comprarán productos de afuera y con ellos la innovación que traen consigo. Está implícito que el fomento de la innovación es un tema de políticas públicas y no tiene por qué afectar de manera alguna a las organizaciones privadas. 
b) Importar a los innovadores, es decir, buscar que las empresas innovadoras se establezcan en el mercado del comprador. Para esto, se utilizarán acuerdos o contratos que hagan viable ese establecimiento, que es muy similar al punto anterior, salvo en la velocidad como llegan las innovaciones.

c) Se propone generar, desde la demanda, soluciones a sus problemas operacionales, propiciando la innovación de sus proveedores, actuales o potenciales, buscando de tener una puerta de ingreso en base a la solución de problemas con soluciones que no existen.

¿Por qué el comprador debe seguir el tercer camino de buscar la innovación desde la demanda? Se tienen varias razones y de diversos tipos, entre ellos:

a) Logra soluciones nuevas (que no existían) a problemas operacionales que al ser instaladas, conllevan a establecer una ventaja competitiva sobre el resto del mercado.

b) Propicia un clima diferente con sus proveedores, actuales o potenciales, en donde además de las normales transacciones económicas, se tiene una relación basada en la búsqueda de la innovación.

c) Los mecanismos que tiene un proveedor para acceder a los mercados son varios, dentro de ellos se tiene estrategias de precios bajos o de diferenciación, pero en base a estatus o mecanismos parecidos, en estos esquemas, el argumento es el de la solución innovadora y el de la diferenciación real contra sus competidores.

d) Encontrar una rutina de innovación es fundamental. Si bien se puede dar la impresión de que la innovación es una cuestión de inspiración, hacer de una invención una aplicación, requiere metodología y trabajo.

e) En un mercado gris, con prácticas a veces no tan éticas o que lindan con el aprovechamiento mercantilista, encontrar un lenguaje de relacionamiento diferente es ciertamente positivo para el ambiente comercial.

Puede parecer simple de realizar, pero como ya se indicó, no es solo un tema de invenciones, es convertir la experiencia y las competencias técnicas en nuevos desarrollos, productos y servicios. Innovar desde la demanda tiene dificultades distintas, ya que innovar requiere habilidades técnicas y de competencias para lograr las ideas nuevas y hallarles una aplicación. En el caso de innovar desde la demanda, se requiere buscar el concurso de otros para que innoven desde las necesidades del demandante, esto es buscar generar un espacio donde esto sea posible. 
¿Cuáles serían las objeciones que podrían tener los proveedores a participar en un proceso de innovación desde la demanda? En términos simples, se podría pensar que no habría objeciones, pero se podrían enumerar algunas dificultades, entre estas tenemos:

a) La primera sería la de recursos. Las empresas no suelen tener, menos en un país como el Perú, recursos para innovar. Aunque no se tienen datos exactos sobre el tema, es notorio que la mayoría de empresas no tiene un área de investigación y desarrollo, quedando esta función en manos solo de empresas grandes, cuya facturación garantiza tener los recursos para solventar esta función.

b) La segunda dificultad, derivada de la primera, involucra la autoestima. Se puede deducir que la innovación, el desarrollo continuo solo es posible hacerlo si se tiene escala, gran facturación, muchos empleados, entre otros.

c) La tercera dificultad sería la de protección de la innovación. ¿Cómo se garantizaría que la innovación aplicada desarrollada por el proveedor sea utilizada solo para beneficio del desarrollador y no para beneficios de terceros que no invirtieron en el desarrollo de la innovación?

d) La cuarta dificultad sería la del proceso mismo. ¿Cómo acceder a los problemas que se quieren resolver?, ¿cómo presentar las ideas?, ¿cómo hacer para volver las ideas productos o servicios?

Es innegable que si se quiere establecer un programa de innovación desde la demanda —entiéndase desde un comprador- deben entenderse claramente las razones para las cuales se establece y mantiene un programa de innovación, e implementar mecanismos que eliminen o alivien las dificultades expuestas. Si el propósito es claro, y en alguna medida trasciende los objetivos de la propia empresa y traslada parte de esos objetivos al crecimiento y fortalecimiento de sus proveedores, se podría decir que el esquema tiene una fortaleza de inicio, que es importante contar para buscar la innovación como elemento permanente y no tener un programa efímero proporcional al entusiasmo de algunos.

Por otro lado, no se ha mencionado hasta este momento el poder de compra. El poder de compra, esto es la importancia real o relativa del comprador (es real cuando el cliente es grande y el monto de transacción también y es relativo cuando el cliente es importante pero el monto de transacción no), puede tener de inicio un gran impulso, dado exclusivamente por ese poder de compra. Ahora bien, también el poder de compra implica una mayor responsabilidad ante los diferentes actores (grupos de interés en la terminología de RSE), por lo que existiría una proporcionalidad entre tamaño de la empresa e impacto en la sociedad. 
Los impactos en la sociedad pueden ser de diversos tipos y en los últimos tiempos ha mantenido especial relieve los temas medioambientales, los relacionados a grupos minoritarios o que de alguna manera son afectados por las operaciones, y los temas de filantropía.

Como se ha explicado anteriormente, la innovación es un tema social, así que se está ante un fenómeno social de importancia. En la terminología de Schumpeter, la destrucción creativa, este hecho que facilita el desarrollo económico de los pueblos, que es producto de la innovación tiene un componente social importante, ya que la innovación conduce a una reconfiguración social, tal como ya se ha detallado. Es entonces propiciar la innovación, una actividad de responsabilidad social empresarial, aun cuando esta tenga como primer usuario a la empresa; el esfuerzo en propiciarla, el buscar que los proveedores compartan una idea y que los obstáculos de un esfuerzo como este desaparezcan o se minimicen, es — reiteramos - una actividad de responsabilidad social empresarial.

Si bien es cierto, la RSE relativa a los proveedores contempla un trato respetuoso y lo que se ha denominado en llamar comercio justo, existen otras formas de relacionar la RSE con el trato con los proveedores. Una primera forma es compartir objetivos sociales, que aun cuando no es muy usual, puede resultar obvio que un programa de RSE de un comprador tendría un crecimiento geométrico si se logra el concurso de sus proveedores. La pregunta sería por qué no es tan frecuente si es tan conveniente. La respuesta pasaría por el horizonte o la falta de competitividad.

En el caso del vendedor no participaría, ya que eso podría ser considerado un sobrecosto y no necesariamente garantizaría (en el pensamiento lógico de un vendedor) la continuidad de la relación con el comprador. El comprador, podría sentir que una participación de los proveedores en sus programas de RSE le quitaría competitividad para escoger una mejor propuesta económica de otro proveedor. Esto implica que la empresa compradora, no considera la práctica de RSE como inherente al negocio y que separa esas prácticas del desarrollo normal de sus actividades.

Dentro de los aspectos sociales que un programa de innovación desde la demanda puede tener, es el de involucrar a otros actores en el esfuerzo de innovar. Tal como se indicó anteriormente en este trabajo, la innovación tiene una parte científica que luego busca ser aplicada. La parte científica en la sociedad, se da normalmente en las universidades y la parte de aplicación en las empresas. Resulta entonces natural para un comprador que quiere promover la innovación, tratar de unir a estos dos actores, de manera que la universidad sea el área de investigación y desarrollo de varias empresas. $\mathrm{Al}$ igual que las universidades, es imperativo tratar de buscar el concurso de los gobiernos, esto es, unir las políticas públicas con las prácticas privadas. 
Hasta este punto, el presente trabajo muestra un esquema conceptual de innovación desde la demanda, contemplando todas las aristas que este concepto podría albergar. Pero así como en la innovación no basta solo con la invención sino que hay que contar con su aplicación, en las páginas siguientes se presentará un caso de estudio real desarrollado en el Perú.

\section{Caso de aplicación. Compañía Minera Antamina y su Programa de Desarrollo de Proveedores de Excelencia}

Como se mencionó anteriormente, este trabajo propone un esquema de innovación aplicado a la cadena de suministro, con un caso de aplicación presentado en la Compañía Minera Antamina - empresa minera peruana-, en el desarrollo de su programa Desarrollo de Proveedores de Excelencia.

Es importante resaltar que programas como el de Desarrollo de Proveedores de Excelencia ponen el foco de las relaciones entre los clientes y proveedores en la innovación. Es notable que los grandes problemas sociales en América Latina deriven, entre otras cosas que no es materia de este trabajo, de la corrupción en la compra de bienes y servicios, especialmente en el sector público aunque también afecta al sector privado. En concordancia con lo expresado líneas atrás, todo programa que haga enfocar los recursos de los proveedores hacia la innovación, desvía la atención de otras prácticas, incluidas entre estas, prácticas corruptas.

A través de este programa, la Compañía Minera Antamina busca cumplir con tres objetivos fundamentales:

a) Desarrollar proveedores capaces de prestar servicios cada vez más complejos tanto a la industria minera local como a otras industrias y países.

b) Aportar de manera creciente al incremento de productividad de la operación desde soluciones con contenido de innovación.

c) Generar a partir de la minería un espacio donde conversen los programas de innovación con la finalidad de difundir y exportar ideas innovadoras.

Para poder cumplir con estos objetivos, el programa Desarrollo de Proveedores de Excelencia busca generar un espacio de colaboración cliente-proveedor para innovar desde la demanda para resolver problemas operacionales de la Compañía Minera Antamina.

El programa gira alrededor de proyectos denominados Desafíos de Alto Valor (DAV), los cuales son el espacio en el cual se generan los concursos que permiten innovar a los proveedores con soluciones que no existen en el 
mercado para problemas operacionales. Los proyectos DAV corresponden a problemas operacionales, los cuales deben contar con los siguientes elementos:

- La solución debe ser presentada e implementada por un proveedor.

- La solución debe contener cierto grado de innovación y/o transferencia tecnológica para el mercado nacional.

- Debe participar en el desarrollo de la solución una universidad y/o centro de Innovación y Desarrollo (I\&D), donde podría generarse una alianza de colaboración entre los proveedores y la academia.

- La solución debe ser replicable para la minería e inclusive otras industrias.

En la búsqueda de resolver los proyectos DAV, el programa busca generar un ambiente de innovación, donde participen diferentes actores dependiendo del tipo de problema operacional que se haya identificado. Estos grupos son los siguientes:

a) El cliente: donde los encargados de la operación son los clientes finales de la soluciones a ser propuestas. Es importante resaltar que un problema operacional puede ser resuelto de varias formas y dependiendo del tipo de soluciones propuestas puede haber más de un área de la operación involucrada en evaluar cuáles son las soluciones más adecuadas a implementar por parte de la Compañía Minera Antamina

b) Proveedor: donde los proveedores, universidades o alianzas de proveedores con universidades, forman parte de un concurso de licitación no tradicional, donde se licitan problemas en búsqueda de innovaciones que los resuelvan de diferentes formas.

c) Articulador: el área logística de la Compañía Minera Antamina cumple un rol importante, ya que son los compradores del área los que están involucrados en todo el proceso del DAV, garantizando la integridad del concurso y brindar los lineamientos que corresponden a proteger la confidencialidad de la información y cumplir de manera ordenada con los objetivos y plazos determinados. Por otra parte, tienen el rol de articuladores, con la finalidad de generar los espacios de trabajo colaborativo entre todos los actores involucrados. En este caso en particular el área de logística trabaja en conjunto con la empresa consultora contratada, quienes en conjunto cumplen el rol de articulador del programa y son los encargados del diseño de los lineamientos estratégicos del mismo. 
Figura 1:

Ecosistema de innovación cartera proyectos DAV 2015

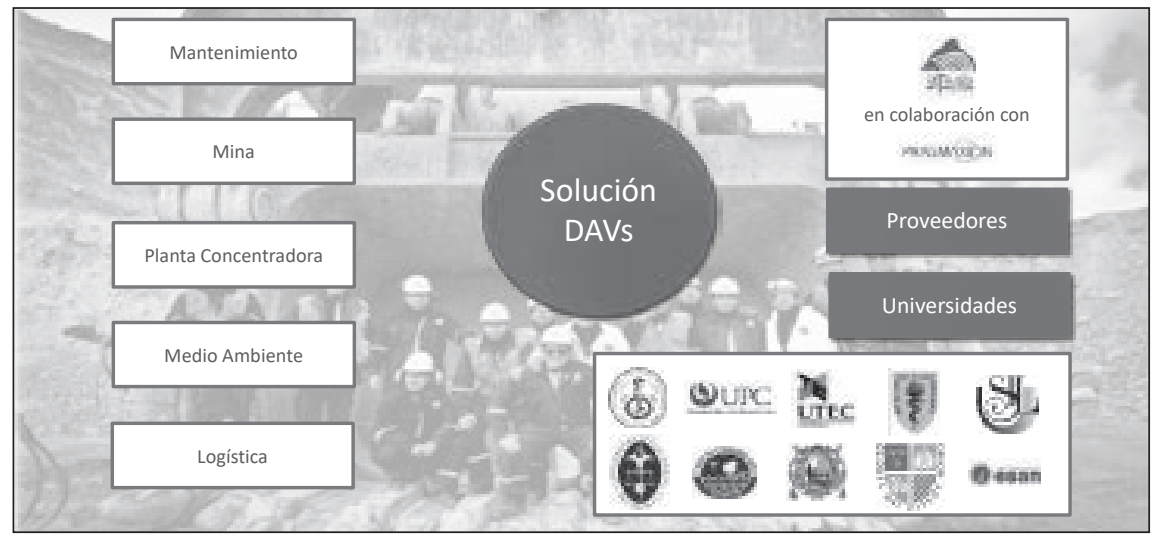

Elaboración propia.

d) Validadores: en algunos casos, las soluciones innovadoras propuestas por los proveedores tienen algunas aspectos que requieren de una validación adicional debido a los cambios que se pueden generar en las condiciones actuales de la operación, por esa razón otras áreas transversales de la Compañía Minera Antamina, como por ejemplo el área de seguridad, e incluso alguna universidad podría ser un validador externo del programa, como por ejemplo en temas de salud y seguridad industrial.

La metodología del programa consiste en generar espacios de colaboración entre los actores mencionados anteriormente. Este proceso se da en diferentes etapas, que se inician con el compartir los desafíos identificados en la operación con los proveedores y universidades, lo cual continúa con un diseño colaborativo de las soluciones entre cliente y proveedor y concluye con una etapa de una nueva oferta y crecimiento de los proveedores a partir de la etapa de implementación.

Los pasos que sigue el programa son los siguientes:

a) Levantamiento de desafíos operacionales: para lo cual se realizan entrevistas con los encargados de la operación con la finalidad de identificar problemas en las diferentes áreas. Estas área son: Operaciones Mina, Planta Concentradora, Mantenimiento, Medio Ambiente y Logística.

b) Construcción de los DAV: una vez identificados estos desafíos operacionales, estos son clasificados en una matriz para hacer un 
ranking de cuáles tienen mayor perfil de ser resueltos a través de un proveedor mediante una solución innovadora y que se encuentren alineados con las necesidades estratégicas tanto del cliente como del proveedor.

Luego de la selección, se preparan las presentaciones a ser expuestas ante los proveedores y universidades en el lanzamiento del programa. Una de las principales distinciones de la cartera del año 2015, es que la Compañía Minera Antamina logró expandir esta iniciativa lanzando proyectos en conjunto con tres de sus principales socios estratégicos; en búsqueda de hacer más eficiente el transporte de los combustible y explosivos, se realizó un trabajo en conjunto con las empresas Repsol, Famesa y Enaex, lo cual fortalece la expansión del programa Desarrollo de Proveedores de Excelencia.

Figura 2:

Cuadro de la clasificación de la cartera de proyectos DAV del año 2014

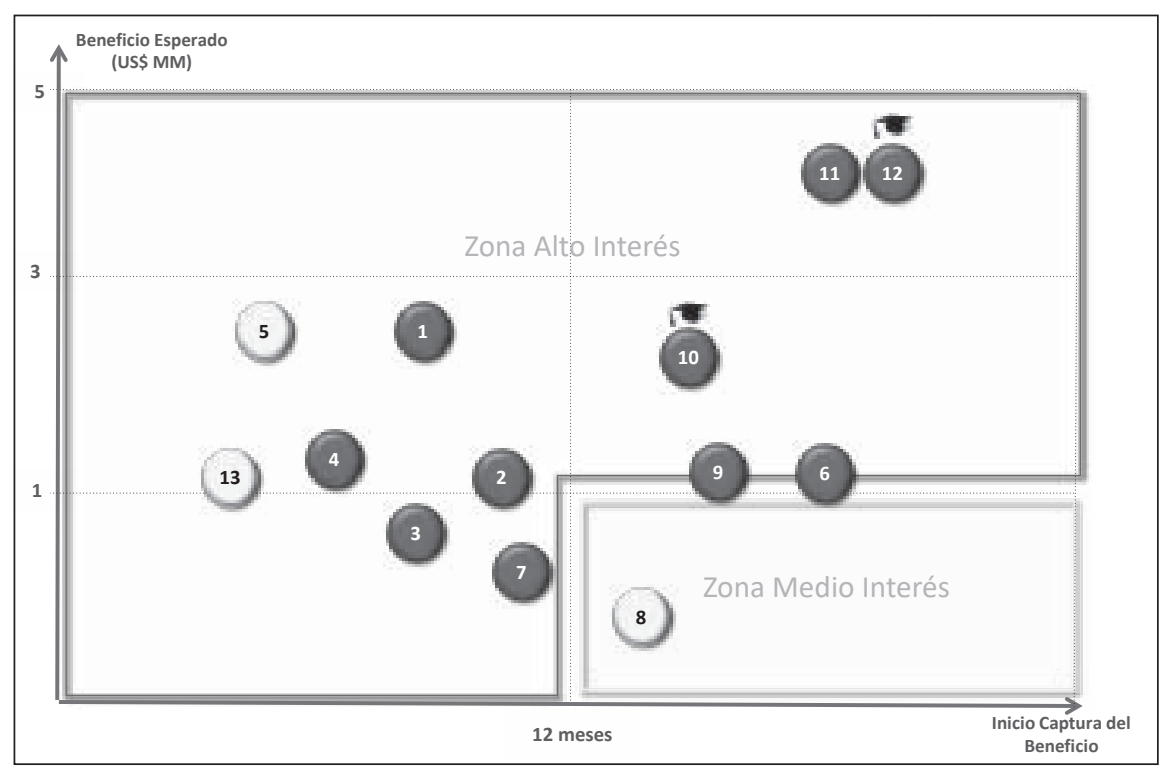

Elaboración propia.

c) Identificación de proveedores: una vez seleccionados los DAV es necesario buscar proveedores sobre la base del tipo de desafío. Las fuentes son diversas pero se busca identificar todas las empresas que puedan aportar una idea innovadora. 
Figura 3:

Síntesis de participación de proveedores y universidades en el programa de Desarrollo de Proveedores de Excelencia de Antamina

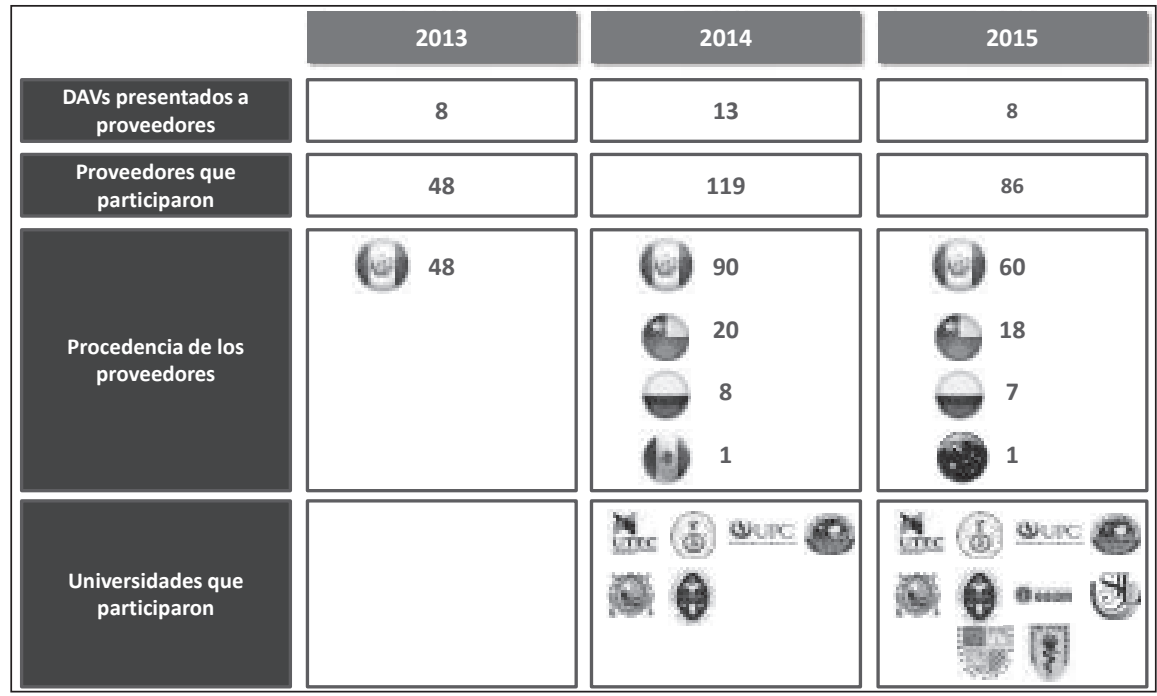

Elaboración propia.

El programa busca proveedores con capacidad de innovar, lo cual ha logrado contar con de un 35\% de proveedores nuevos para la Compañía Minera Antamina, que corresponden a las tres carteras con un total de 29 proyectos DAV con la participación de alrededor de 150 proveedores y de 10 de las principales universidades del Perú.

Una de las particularidades de este programa es que todos los proveedores que son identificados, son invitados a participar de todos los DAV de la cartera, donde en muchas casos los proveedores postulan a participar de los desafíos donde no habían sido considerados inicialmente, presentando soluciones innovadoras y no identificadas hasta ese momento.

d) Lanzamiento del programa: anualmente la Compañía Minera Antamina realiza un evento para compartir los DAV con los proveedores y universidades que han sido convocadas y que han mostrado interés en participar. En el evento se realizan las presentaciones de cada DAV, mostrando la problemática del desafío, la situación y características actuales, junto con los beneficios y los indicadores esperados fruto de la resolución del problema. 
Figura 4:

Lanzamiento del Programa, el 6 de marzo del año 2015 en la universidad ESAN

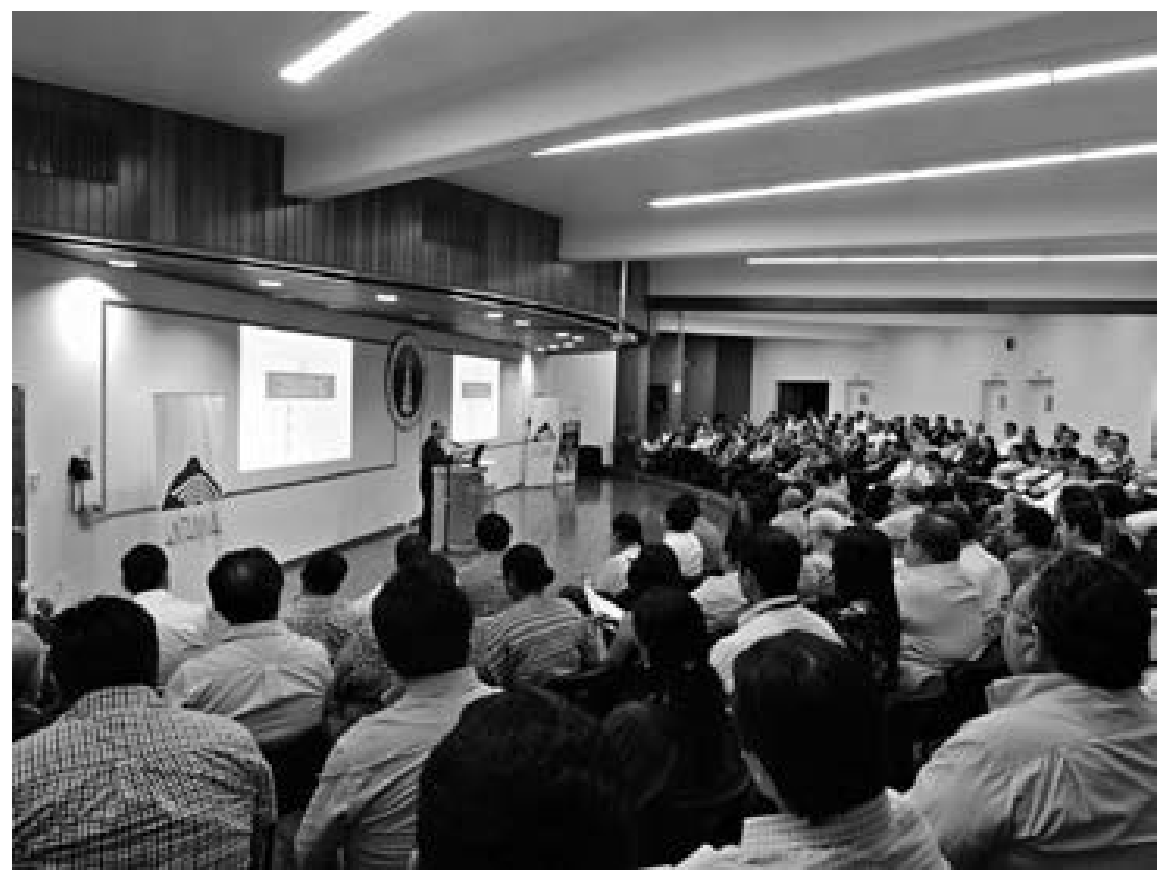

Foto: Antamina.

e) Diseño colaborativo de las soluciones: una vez que los proveedores y universidades reciben la información en el lanzamiento del programa, tienen un espacio de tiempo para buscar generar alianzas para el diseño de su solución, con lo que el programa presenta un modelo de cooperación proveedor universidad, el cual se muestra en la Figura 6. Hay que añadir que durante la cartera del año 2015 se han implementado 25 convenios de cooperación para el desarrollo de las soluciones.

Luego de la generación de alianzas, los proveedores y universidades pueden presentar sus propuestas como consorcio o de manera independiente, para el caso que no hayan generado una alianza. Las propuestas son presentadas como estrategias técnicas para abordar el desafío. Una vez recibidas las estrategias, se seleccionan las ideas más innovadoras y que se encuentran más alineadas a cumplir los objetivos de cada DAV. 
Figura 5:

Presentación del DAV 2015.1, por parte del equipo de logística de Antamina en conjunto con Repsol durante el lanzamiento del Programa del año 2015

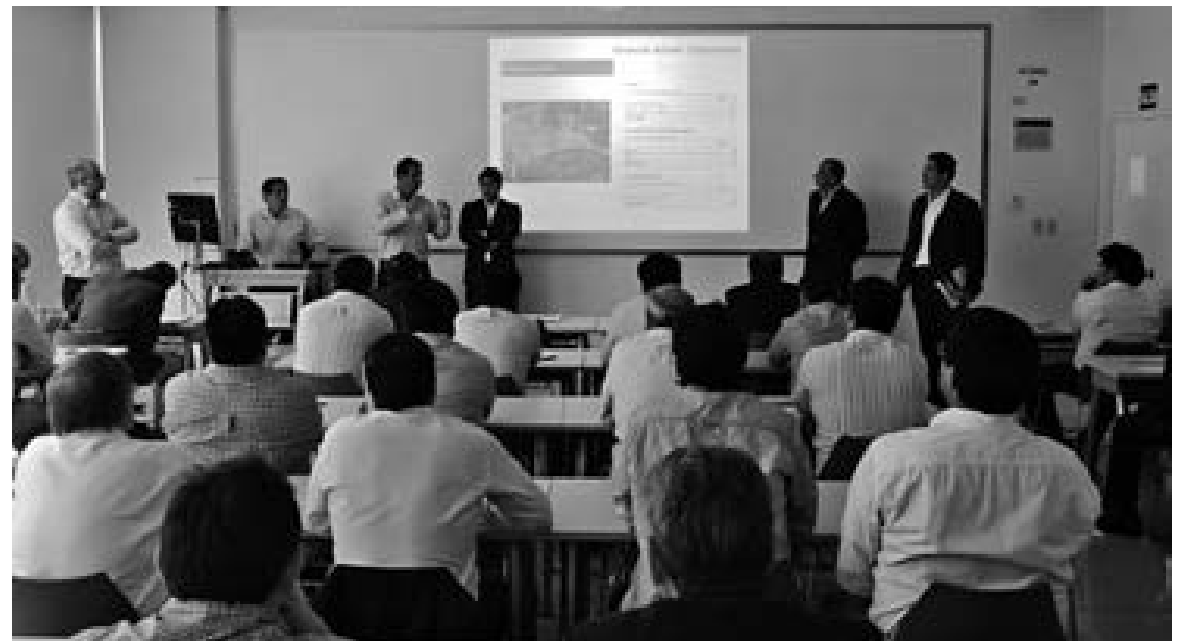

Foto: Antamina.

Este grupo de proveedores pre seleccionados participan de una primera sesión colaborativa para presentar su estrategia y tener un espacio de conversación para afinar sus ideas y preparar un modelo de negocio orientado hacia los objetivos del DAV.

El proceso continúa con visitas a las operaciones y con más sesiones colaborativas, de manera de poder seleccionar las mejores propuestas, que en la siguiente etapa tendrán una prueba piloto.

f) Implementación de propuestas y crecimiento del proveedor: los proveedores seleccionados podrán probar sus soluciones y prototipos en las pruebas piloto que se realizarán. En estas pruebas piloto se establece un monitoreo de los indicadores establecidos para verificar los resultados de la solución y el cumplimiento del protocolo de pruebas previamente establecido. Las pruebas piloto usualmente se llevan a cabo con base en modelos de negocio de riesgo compartido donde la Compañía Minera Antamina facilita un campo de pruebas controlado y el proveedor realiza pruebas piloto en las cuales se compromete al cumplimiento de los indicadores establecidos.

Luego de comprobar el éxito de las pruebas piloto, se genera un nuevo espacio de conversación colaborativo para la generación de un acuerdo. Hay que resaltar que el proveedor mantiene el $100 \%$ de la propiedad intelectual de su solución. También hay que resaltar que crece su gama de productos y su capacidad para generar soluciones. 
Figura 6:

Modelo propuesto de cooperación entre proveedores y universidades

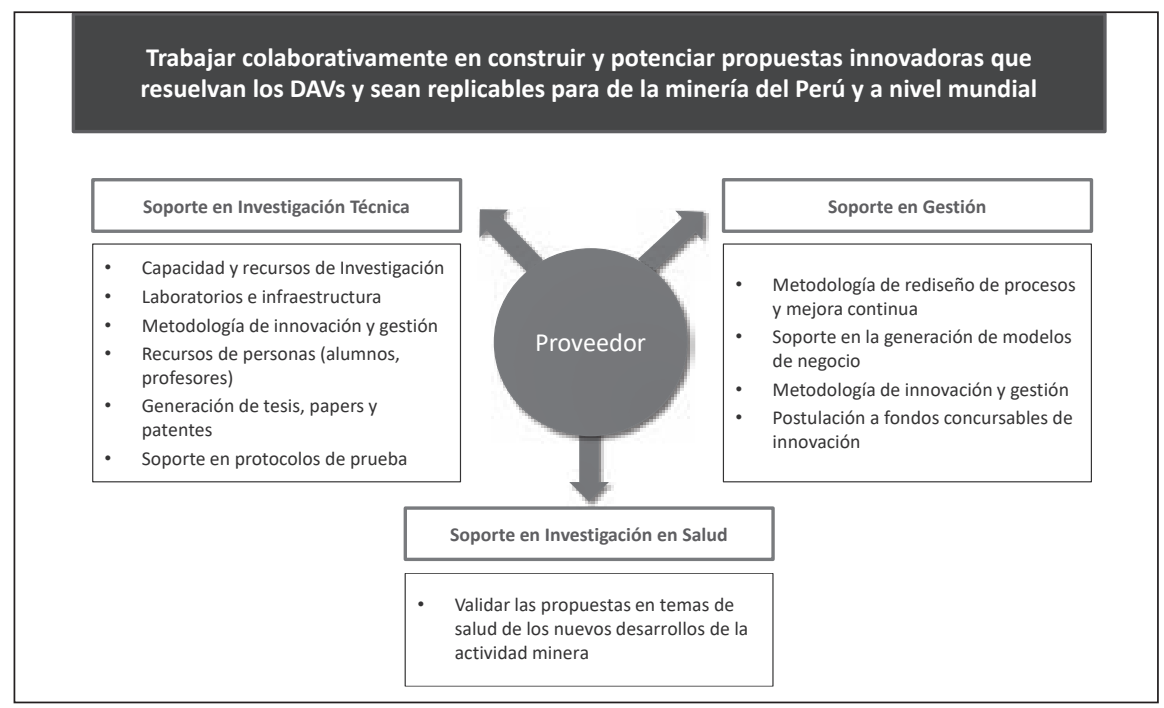

Elaboración propia.

Figura 7:

Visita a mina por los DAV

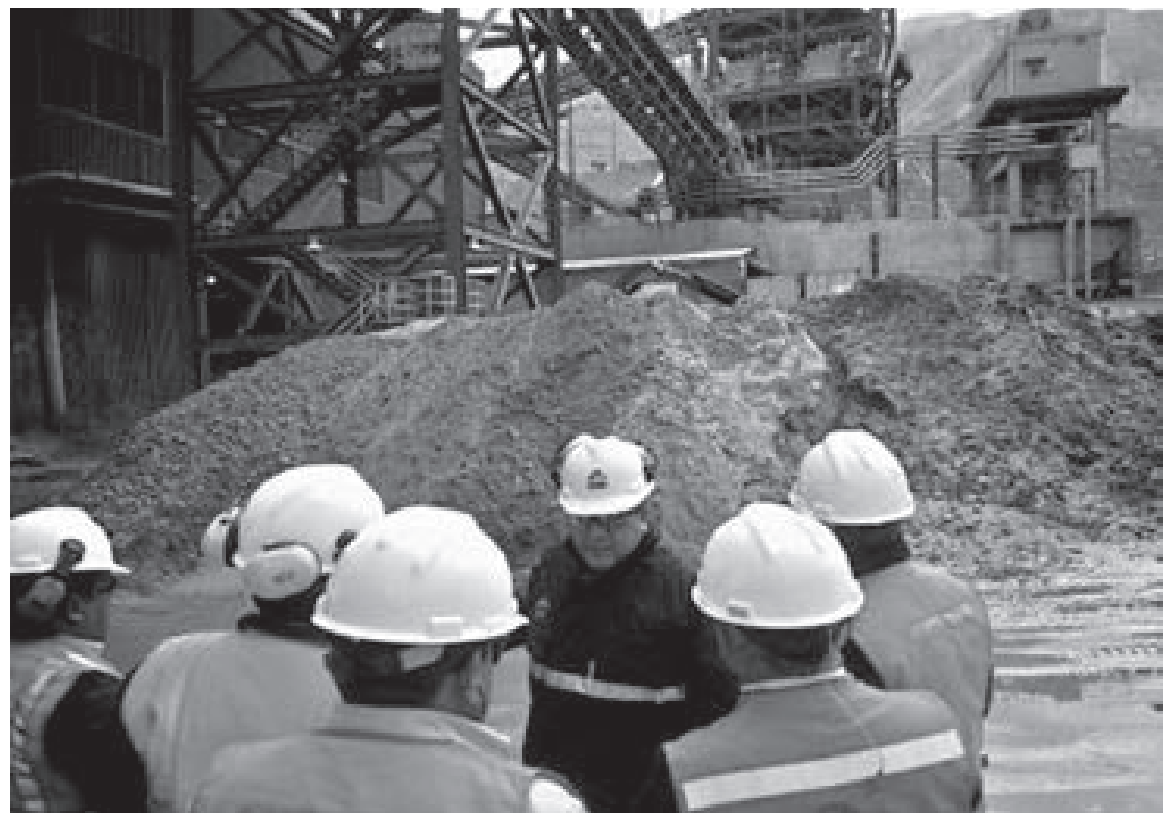

Foto: Antamina. 
Sobre la base de la descripción de los procesos y metodología del programa, se han logrado distintos resultados en diferentes etapas del proceso, entre los cuales destacan las siguientes soluciones a los proyectos DAV:

- Disminuir en al menos un día los tiempos de round trip en el transporte Lima-Mina-Lima, desafío en el cual hubo dos empresas proveedoras con propuestas innovadoras.

El caso de la empresa Transaltisa, que traslada bolas de acero en el tramo de Lima a la mina y retorna con plomo o molibdeno. Este proveedor buscaba reducir los tiempos de viaje round trip de cuatro días a tres, consistentes en la mejora y desempeño de los tiempos empleados en los procesos de carga y descarga, para lo cual asignaron un tracto remolcador y tres semirremolques destacados en mina, de tal manera que cambiaron el procedimiento habitual realizando los trabajos de descarga en horario nocturno en condiciones de seguridad controladas y desarrollando un modelo de negocio basado en la cantidad de días de duración del round trip. Ambos cambios generaron una innovación en la oferta del proveedor con respecto a su oferta inicial y permitieron replicarlo en un contrato para todos los viajes de la flota.

Por otra parte, la empresa Ransa, que traslada carga diversa desde sus almacenes en Lima hacia la mina, se propusieron reducir el round trip de 3,74 días en promedio a 2 días, para lo cual se realizó un trabajo colaborativo mediante el cual se lograron estandarizar los diferentes horarios y condiciones de la ruta al igual que la carga y descarga en mina y en los almacenes de Ransa como se aprecia en la Figura 8. Esto llevó a una estandarización en los tiempos de salida del transportista hacia la mina y significó una reducción en los tiempos y optimización de recursos para el proveedor.

Tanto para Transaltisa como para Ransa, sus propuestas fueron monitoreadas a través de pruebas piloto con un máximo de dos viajes por día. Luego de comprobar el éxito de los innovadores esquemas de transporte se procedió a realizar contratos con modelos de cobro variable basados en la duración de los respectivos round trip de cada viaje. 
Figura 8:

Hoja de ruta propuesta por Ransa para reducción del round trip

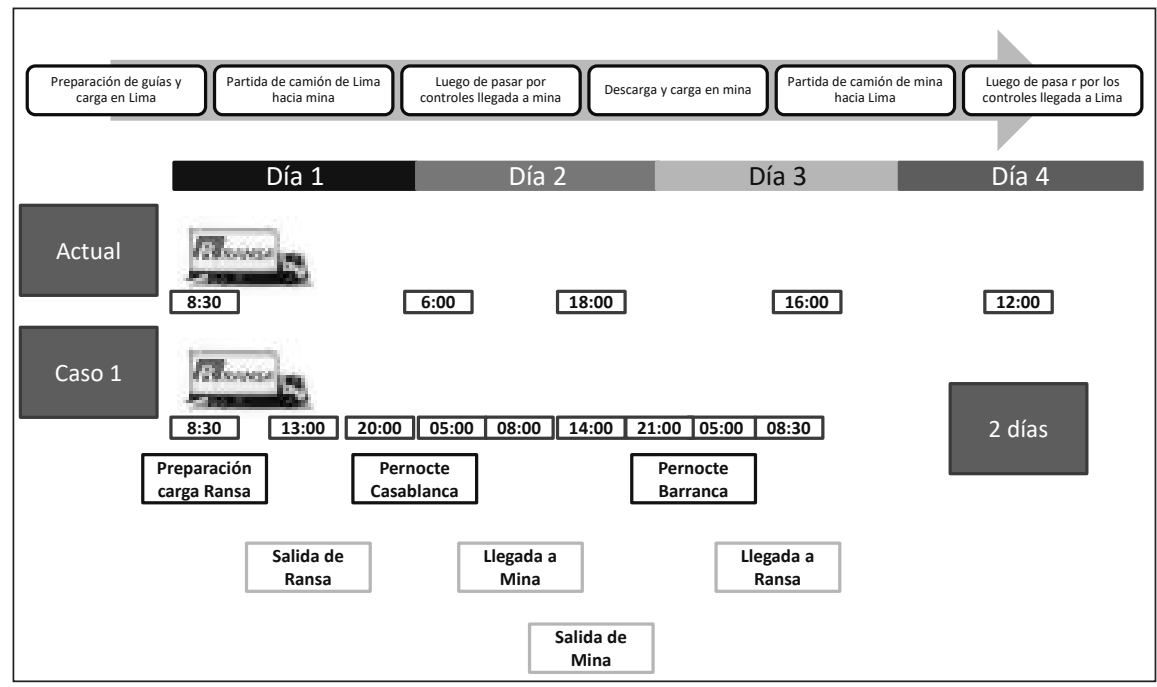

Elaboración propia.

- Hacer más eficiente el transporte de los neumáticos con aro 63 de los camiones de acarreo, desafío en el cual hubo dos empresas proveedoras con propuestas innovadoras con respecto al modelo tradicional donde se trasladaban un máximo de cinco llantas debido al tipo de camión o cama baja que cumplía con las condiciones de las carreteras en la ruta LimaAntamina y con las regulaciones de la ley y seguridad en el Perú.

Las empresas transportistas Dinet y Ransa lograron desarrollar un tipo de cama baja innovadora que marcó el hito de transportar seis llantas de aro 63 en las condiciones de las carreteras a nivel nacional, lo que ahora es un estándar para el transporte de neumáticos en la Compañía Minera Antamina.

Finalmente, es importante volver a mencionar que el programa de Desarrollo de Proveedores de Excelencia de la Compañía Minera Antamina tiene como cliente final al Perú y busca contribuir al incremento de la competitividad del país través de la innovación y del desarrollo de proveedores en la industria minera, por ese motivo este programa ha sido compartido a través de las presentaciones en los tres distintos lanzamientos del programa y en diferentes reuniones sobre iniciativas de innovación con algunas de las principales empresas motoras de otros rubros del país como lo son Alicorp, Backus y Gloria en el rubro del consumo masivo, a quienes se suman Repsol y Pluspetrol en el rubro de petróleo y energía, al igual que Ransa, Dinet y Yobel en lo referido a transportes, junto con Ferreyros y el grupo Graña y Montero quienes son parte fundamental del crecimiento económico del Perú. 


\section{Referencias}

Ageron, B., LAVASTRE, O., \& SPALANZANI, A. (2012). «Innovative supply chain practices: the state of French companies». Supply Chain Management: An International Journal. 18(3), 265-276. https://doi.org/10.1108/scm-03-2012-0082

Ambrose, E., Marshall, D., \& LYNCH, D. (2010). «Buyer supplier perspectives on supply chain relationships». International Journal of Operations \& Production Management, 30(12), 1269-1290. https://doi. org/10.1108/01443571011094262

BERISTAIN, L. (2009) «Una revisión de la interpretación económica sobre la innovación». Journal of Technology Management \& Innovation, 4(4), 139-149. http://www. redalyc.org/articulo.oa?id=84712862012

BöGENHOLD, D. (2014). «Schumpeter's Idea of a Universal Social Science». International Atlantic Economic Society, 42 (1), 205-215. . https://doi.org/10.1007/ s11293-014-9409-3

CANning, L., \& Hanmer-Lloyd, S. (2007). "Trust in buyer-seller relationships: the challenge of environmental (green) adaptation».EuropeanJournalofMarketing, 41(9/10), 1073-1095. https://doi.org/10.1108/03090560710773354

CoX, A., LondSALE, C., WATSON, G., \& QIAO, H. (2003). «Supplier relationship management: a framework for understanding managerial capacity and constraints». European Business Journal, 2003.

Dabic, M., Cvijanovic, V., \& GonZÁLEZ-Loureiro, M. (2011). «Keynesian, post-Keynesian versus Schumpeterian, neo-Schumpeterian: An integrated approach to the innovation theory». Management Decision, 49(2), 195-207. https://doi. org/10.1108/00251741111109115

Drake, M., \& Schlachter, J. (2007). " A Virtue-Ethics Analysis of Supply Chain Collaboration». Journal of Business Ethics, 82(7), 851-864. . https://doi. org/10.1007/s10551-007-9597-8

DUMAY, J., RooneY, J., \& MARINI, L. (2013). «An intellectual capital-based differentiation theory of innovation practice». Journal of Intellectual Capital, 14(4), 608-633. https://doi.org/10.1108/ JIC-02-2013-0024

Ellram, L., \& CARR, A. (1994). «Strategic Purchasing: A History and review of the Literature». International Journal of Purchasing and Materials Management, 30(2), 10-18. https://doi.org/10.1111/j.1745-493X.1994.tb00185.x

Galambos, L. (2011). «A comment on Nathan Rosenberg's question: "Was Schumpeter a Marxist"». Industrial and Corporate Change, 20(4), 1223-1227. https://doi. org/10.1093/icc/dtr038

Galindo, M., Ribeiro, D., \& MÉNDEZ, M. (2012). «Innovación y crecimiento económico: Factores que estimulan la innovación». Cuadernos de Gestión, 12(1), 51-58. https://doi.org/10.5295/cdg.110309mg

Gallego-Álvarez, I., Prado-Lorenzo, J., \& García-Sánchez, I. (2011). «Corporate social responsibility and innovation: a resource-based theory». Management Decision, 49(10), 1709-1727. https://doi.org/10.1108/00251741111183843 
GefFen, C., \& RothenberG, S. (2000). «Suppliers and environmental innovation. The automotive paint process». International Journal of Operations \& Production Management,20(2),166-186.https://doi.org/10.1108/01443570010304242

Gueimonde-Canto, A., González-Benito, J., \& García-VÁzquez, J. (2011). «Competitive effects of co-operation with suppliers and buyers in the sawmill industry». Journal of Business \& Industrial Marketing, 26(1), 58-69. https:// doi. org/10.1108/08858621111097210

Hirakubo, N, Kublin, M, \& Topol, M. (2000). «The Myth of Japanese Buyer-Supplier Relationships», American Journal of Business, 15(2), 85 92. https://doi. org/10.1108/19355181200000014

JAJJA, M., BRAH, S., HASSAN, S., \& KANNAN, V. (2014). "An examination of product innovation and buyer-supplier relationship in Pakistani firms». International Journal of Productivity and Performance Management. 63(8), 1031-1045. https://doi.org/10.1108/ IJPPM-02-2013-0023

JefFries, F., \& REED, R. (2000). «Trust and adaptation in Relational Contracting». The Academy of Management Review, 25(4), 873-882. https://doi.org/10.5465/ AMR.2000.3707747

Jensen, J., MunksgaARd, K., \& ARLBJøRn, J. (2013). «Chasing value offerings through green supply chain innovation». European Business Review, 25(2), 124-146. https://doi.org/10.1108/09555341311302657

JohANNESSEN, J. (2013). «Innovation: a systemic perspective developing a systemic innovation theory». Kybernetes, 42(8), 1195-1217. https://doi. org/10.1108/K-04-2013-0069

Johnston, D., Murat, M. (2008). «The climate for co-operation: buyer-supplier beliefs and behavior». International Journal of Operations \& Production Management. 28(9), 875-898. https://doi.org/10.1108/01443570810895294

Kiм, Y., Choi, T., \& Skilton, P. (2014). «Buyer-supplier embeddedness and patterns of innovation». International Journal of Operations \& Production Management. 35(3), 318-345. https://doi.org/10.1108/01443570810895294

KöHLER, H., \& GonzÁLEz, S. (2014). «Elementos para un concepto sociológico de innovación». Empiria: Revista de Metodología de Ciencias Sociales, 29(1), 6788. http://dx.doi.org/10.5944/empiria.29.2014.12942

KraljIC, P. (1983). «Purchasing must become Supply Management». Harvard Business Review, September-October 1983, 109-117. http://co-buy.sakura.ne.jp/ materials/20110129_kanto_no30.pdf

Kumar, S., BragG, R., \& Creinin, D. (2003). «Managing Supplier Relationships». Quality Progress, 36(9), 24-30. https://search.proquest.com/docview/214764640/ fulltextPDF/A8FD2925029D4D6FPQ/1?accountid=28391

KurtakKo, J. (2014). «Schumpeter's challenge to economists: History, theory and statistics as key competencies and sociology as a vision for the future». American Journal of Economics and Sociology, 73(1), 32-57. http:// onlinelibrary.wiley.com/doi/10.1111/ajes.12060/full 
KuRz, H. (2012). «Schumpeter and Marx: a comment on a debate». Industrial and Corporate Change, 22(2), 577-584. https://academic.oup.com/icc/ article/22/2/577/683859/Schumpeter-and-Marx-a-comment-on-a-debate

LAU, G. \& GoH, M. (2005). «Buyer Seller relationships in the PCB industry», Supply Chain Management, 10(3/4), 302-312. https://doi. org/10.1108/13598540510612776

LEE, K. \& KIM J. (2009). «Current status ofCSR in the realm of supply management: the case of the Korean electronicsindustry».SupplyChain Management:AnInternational Journal, 14(2), 138-148. https:// doi.org/10.1108/13598540910942000

Lee, C., Kwon, I., \& Severance, D. (2007). «Relationship between supply chain performance and degree of linkage among supplier, internal integration, and customer». Supply Chain Management: An International Journal, 12(6), 444452. https://doi.org/10.1108/13598540710826371

LóPEZ, G. (2006). «Perspectivas para el análisis de la innovación: un recorrido por la teoría». Cuadernos de Administración Bogotá (Colombia), 19(31), 243-273. http://www.redalyc.org/html/205/20503110/

LÜlfESMANN, C. (2001). «Incomplete Contracts. Non-Contractible Quality and Renegotiation». Contributions to Theoretical Economics, 1(1), 1-45. DOI: https://doi.org/10.2202/1534-5971.1017

Marshall \& Rossman (1999). Design Qualitative Research (3rd. Edition). London: SAGE Publications.

Minguela-RAta, B., FernándeZ-MenéndeZ, J., \& Fossas-Olalla, M (2013). «Cooperation with suppliers, firm size and product innovation». Industrial Management \& Data System, 114(3), 438-455. https://doi.org/10.1108/IMDS-08-2013-0357

Malhotra, D. \& MuRnighan, K. (2002). «The effects of Contracts on Interpersonal Trust». Administrative Science Quarterly, 47(3), 534-559. http://journals. sagepub.com/doi/pdf/10.2307/3094850

Murphy, P., \& Poist, R. (2002). «Green perspectives and practices: a comparative logistics study». Supply Chain Management: An International Journal, 8(2), 122-131. https://doi.org/10.1108/13598540310468724

Ogden, J., Petersen, K., CARTer, J. \& MonczKa (2005). «Supply Management Strategies for the Future: A Delphi Study». Journal of Supply Chain Management, 41(3), 29-48. https://doi.org/10.1111/j.1055-6001.2005.04103004.x

Polo, Y., \& CAMBra, J. (2007). «Importance of company size in long-term orientation of supply function: an empirical research». Journal of Business \& Industrial Marketing, 22(4), 236-248. https://doi.org/10.1108/08858620710754504

Porter, M. (1991). La ventaja competitiva de las naciones. Buenos Aires: Editorial Vergara, 1991. https://s3.amazonaws.com/academia.edu. documents/35621855/EL_EXITO_EN_LOS_NEGOCIOS_INTERNACIONALES_ PORTER.pdf?AWSAccessKeyId=AKIAIWOWYYGZ2Y53UL3A\&Expires $=150$ 8975901\&Signature=PgvM3e4F8MW5BjfGXh04vADY1\%2BU\%3D\&respon se-content-disposition=inline \%3B\%20filename\%3DLa_ventaja_competitiva_ de_las_naciones.pdf 
PRIOR, D (2012). «The effects of buyer-supplier relationships on buyer competitiveness». Journal of Business \& Industrial Marketing. 27(2), 100-114. https://doi. org/10.1108/08858621211196976

Rogerson, W. (1992). «Contractual Solutions to the Hold-Up Problem». JReview of Economic Studies, 59(1), 777-794. https://doi.org/10.2307/2297997

SANDBERG, E. (2007). «Logistics collaboration in supply chains: practice vs. theory». The International Journal of Logistics Management, 18(2), 274-293. https:// doi.org/10.1108/09574090710816977

SAViotti, P., \& GAFFARD, J. (2008). «Preface for the special issue of JEE on 'innovation, structural change and economic development'». Journal of Evolutionary Economy, 18(1), 115-117. https://doi.org/10.1007/s00191-007-0085-1

Schmitz, P. (2001). «The Hold-Up Problem and Incomplete Contracts: A survey of recent topics in Contract Theory». Bulletin of Economic Research, 53(1), 1-17. https://doi.org/10.1111/1467-8586.00114

SoOSAY, C., Hyland, P., \& FERRER, M. (2008). «Supply chain collaboration: capabilities for continuous innovation». Supply Chain Management: An International Journal, 13(2), 160-169. https://doi.org/10.1108/13598540810860994

Sternquist, B., Finnegan, C., \& Chen, Z. (2008). «Adding Value To Buyer-Supplier Relationships In China». Journal of Asia Business Studies, 3(1), 1-11. https:// doi.org/10.1108/15587890880000486

Stewart, I., \& FEnN, P. (2006). «Strategy: The motivation for innovation». Construction Innovation, 6(1), 173-185. https://doi.org/10.1108/14714170610710703

Teece, D., Peteraf, M., \& Lieh, S (2016). «Dynamic Capabilities and Organizational AgILITY: Risk, UNCERTAINTY, AND STRATEGY IN THE INNOVATION ECONOMY». CALIFORNIA MANAGEMENT REVIEW, 58(4), 13-35.

VALLE, S., \& VÁsquez-Bustelo, D (2009). «Inclusión de los proveedores en el proceso de desarrollo de nuevos productos. Un análisis de la industria española». Universia Business Review, | ISSN: 1698-5117, 62-74. http://digibuo.uniovi. es/dspace/bitstream/10651/11136/1/Inclusionproveedores.pdf

WaStI, S., KozAN, M., \& Kuman, A. (2006). «Buyer-supplier relationships in the Turkish automotive industry». International Journal of Operations \& Production Management,26(9),947-970.https://doi.org/10.1108/01443570610682580

Williamson, O. (1989). Las Instituciones Económicas del Capitalismo. México: Fondo de Cultura Económica.

YIN, R. (2003). Case Study Research (3rd. Edition). London: SAGE Publications.

Yoguel, G., Barletta, F., \& Pereira, M. (2013). «De Schumpeter a los postschumpeterianos: Viejas y nuevas dimensiones analíticas». Revista Problemas del Desarrollo, 174 (44), 35-59. http://www.scielo.org.mx/pdf/ prode/v44n174/v44n174a3.pdf 